Technology Development

Division

Technology Development

Dhision

Technology Development

Division

Technology Development Division

Technology Development Division

\title{
Review of Free-Surface MHD Experiments and Modeling
}

Technology Development

Division

Trohnology Devetopment

Division

Technology Development

Division

Technology Development

Division

Technology Development

Division

Technology Development

Division

Techmology Development

Division

Technology Development

Division

Techology Development RECEIVFR

Sergei Molokov, Coventry University Claude B. Reed, Technology Develoment

Division

OS. 1

Techndogy Development

Diviston

Technology Development

Division

Technology Development

Dhision

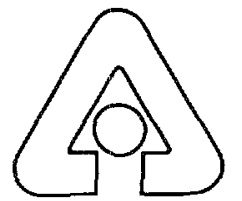

Argonne National Laboratory, Argonne, Illinois 60439

operated by The University of Chicago

for the United States Department of Energy under Contract W-31-109-Eng-38

Fusion Power program

Fusion Power Program

Fuslon Power program

Fusion Power Program

Fusion Power Program

Fuslon Power Program

Fuslon Power Program

Fuslon Power Program 
Argonne National Laboratory, with facilities in the states of Illinois and Idaho, is owned by the United States government, and operated by The University of Chicago under the provisions of a contract with the Department of Energy.

\section{DISCLAIMER}

This report was prepared as an account of work sponsored by an agency of the United States Government. Neither the United States Government nor any agency thereof, nor The University of Chicago, nor any of their employees or officers, makes any warranty, express or implied, or assumes any legal liability or responsibility for the accuracy, completeness, or usefulness of any information, apparatus, product, or process disclosed, or represents that its use would not infringe privately owned rights. Reference herein to any specific commercial product, process, or service by trade name, trademark, manufacturer, or otherwise, does not necessarily constitute or imply its endorsement, recommendation, or favoring by the United States Government or any agency thereof. The views and opinions of document authors expressed herein do not necessarily state or reflect those of the United States Government or any agency thereof, Argonne National Laboratory, or The University of Chicago.

Available electronically at http:/www.doe.gov/bridge

Available for a processing fee to U.S. Department of Energy and its contractors, in paper, from:

U.S. Department of Energy

Office of Scientific and Technical Information

P.O. Box 62

Oak Ridge, TN 37831-0062

phone: (865) 576-8401

fax: (865) 576-5728

email: reports@adonis.osti.gov 


\section{DISCLAIMER}

Portions of this document may be illegible in electronic image products. Images are produced from the best available original document. 


\section{REVIEW OF FREE-SURFACE MHD EXPERIMENTS AND MODELING}

S. Molokov, Coventry University

C. B. Reed, Argonne National Laboratory

Argonne National Laboratory. 9700 South Cass Avenue Argonne, IL 60439

Work supported by the Office of Fusion Energy Sciences

U.S. Department of Energy Under Contract W-31-109-ENG-38 


\section{Contents}

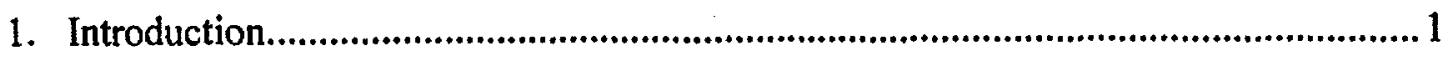

2. Magneto hydrodynamic equations and boundary conditions................................ 2

2.1 Governing equations................................................. 2

2.2 Boundary conditions at the solid walls............................... 4

2.3 Boundary conditions at the free surface................................ 4

2.4 Dimensionless parameters........................................ 5

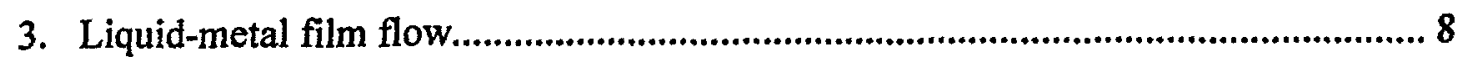

3.1 Fully developed flows............................................. 8

3.1.1 Insulating walls........................................... 9

3.1 .2 Conducting walls........................................... 10

3.1.3 Other studies................................................ 11

3.2 Inclination of the field................................................ 12

3.3 Three-dimensional effects and film stability........................... 13

3.4 Wettability of solid walls and rivulets.................................. 14

3.5 The meniscus....................................................... 17

3.6 Plasma wind.......................................................... 17

3.7 The effect of imperfect insulation of coatings......................... 17

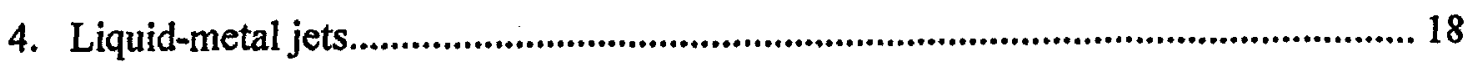

4.1 Three-dimensional effects............................................ 18

4.2 Spatially varying field............................................. 19

4.3 Jet stability in a strong transverse magnetic field....................... 19

4.4 Impact of a jet on solid wall or a liquid metal surface................... 19

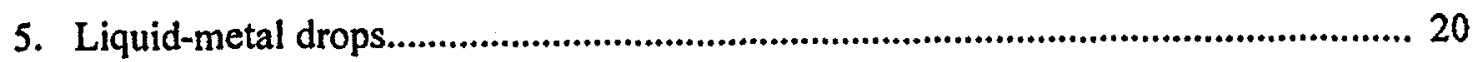

$5.1 \mathrm{Jet} /$ film atomizer................................................... 20

5.2 Spatially varying film............................................... 20

5.3 Drop stability/oscillations in a strong transverse magnetic field............ 21

$5.4 \mathrm{Impact}$ of a drop on solid wall/shallow liquid metal layer................ 22

5.5 Thermo capillary convection....................................... 23 
6. Other effects common to all designs........................................... 24

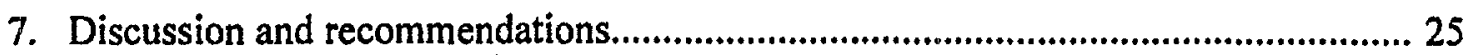

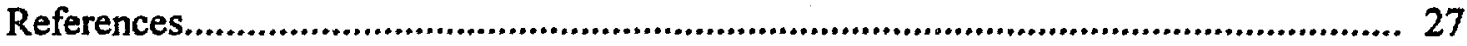

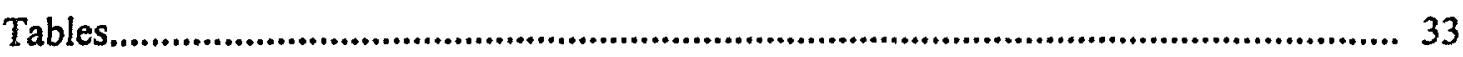

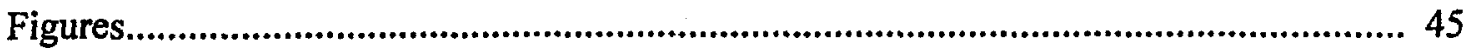




\section{Introduction}

This review paper was prepared to survey the present status of analytical and experimental work in the area of free surface MHD and thus provide a well informed starting point for further work by the Advanced Limiter-diverter Plasma-facing Systems (ALPS) program. ALPS were initiated to evaluate the potential for improved performance and lifetime for plasma-facing systems. The main goal of the program is to demonstrate the advantages of advanced limiter/diverter systems over conventional systems in terms of power density capability, component lifetime, and power conversion efficiency, while providing for safe operation and minimizing impurity concerns for the plasma. Most of the work to date has been applied to free surface liquids. A multi-disciplinary team from several institutions has been organized to address the key issues associated with these systems. The main performance goals for advanced limiters and diverters are a peak heat flux of $>50 \mathrm{MW} / \mathrm{m}^{2}$, elimination of a lifetime limit for erosion, and the ability to extract useful heat at high power conversion efficiency $(-40 \%)$. The evaluation of various options is being conducted through a combination of laboratory experiments, modelling of key processes, and conceptual design studies.

Free surface plasma facing components (PFCs) offer the potential to solve the lifetime issues limiting current solid surface designs for tokamak reactors by eliminating the problems of erosion and thermal stresses accompanying solid surface designs. The moving PFC free surfaces provide the possibility of absorbing impurities and possibly helium for removal outside of the plasma chamber. Free surface PFCs may also offer more creative possibilities for heat removal and higher thermal conversion efficiencies for the entire system. Design requirements for PFCs include handling $\sim 50 \%$ of the plasma heat flux and $-90 \%$ of the ion flux [28]. Early work on PFCs has been reviewed in [5], [10], [48] and [61].

Liquid metal free surface PFCs can be broken down into three main groups: 1) a film flowing over a solid substrate, 2) a droplet curtain, and 3) a jet curtain. Of these three, the droplet curtain and the jet curtain are thought to be least affected by the presence of the magnetic field confining the plasma. Both droplet and jet MHD flows are definitely influenced by the presence of magnetic fields, however. Qualitatively, a uniform magnetic field tends to stabilize the geometry of a droplet or jet flow; surface instabilities are suppressed and the flow field appears to be much more "organized". Because of the significant influence of a magnetic field on the performance of all three of these PFC concepts, it is necessary to consider MHD effects when modelling, designing and testing these free surface systems. 


\section{Magnetohydrodynamic Equations And Boundary Conditions}

We will be concerned with free-surface flows of liquid metals. A liquid metal is an incompressible, viscous, electrically conducting fluid, characterised by the following thermo physical properties: $\sigma_{*}$, electrical conductivity, $\rho_{*}$, density, $\nu_{*}$, kinematics viscosity, $\gamma_{*}$, surface tension coefficient, and $\kappa_{*}$, thermal diffusivity (Table 2.1). All of these quantities, in general, are functions of temperature, but in this survey they are considered to be constant. Because of sufficiently high fluid velocity buoyancy is not expected to be important in most diverter elements, except maybe in collector pools. Therefore, the fluid density is considered to be constant as well.

In this Section the mathematical formulation of the problem is given. First, the governing equations and the boundary conditions are presented, and then the important dimensionless parameters are discussed.

\subsection{Governing equations}

The magneto hydrodynamic liquid-metal flow is characterised by the following dimensional quantities:

- the fluid velocity $\mathbf{v}$.,

- the magnetic field $B$.,

- the electric current density $\mathbf{j}$.,

- the electric potential $\phi$.,

- the pressure $p_{*}$,

- the temperature $T$.

In this paper dimensional quantities are denoted by letters with asterisks, while their dimensionless counterparts - with the same letters but without the asterisks.

By assuming that the magnetic Reynolds number is small, we neglect the effect of the induced magnetic field on the fluid flow, so that $\mathbf{B}$. denotes the external magnetic field. Then the equations governing the liquid metal flow in the induction less approximation are [35]: 


\section{Momentum equation}

$$
\rho_{*} v_{*} \nabla_{*}^{2} v_{*}+j_{*} \times B_{*}=\nabla_{*} p_{*}+\rho_{*} g_{*} \hat{e}_{g}+\rho_{*}\left\{\left(v_{*} \cdot \nabla_{*}\right) v_{*}+\frac{\partial v_{*}}{\partial t_{*}}\right\},
$$

\section{Ohm's law}

$$
\mathrm{j}_{*}=\sigma_{*}\left[-\nabla_{*} \phi_{*}+\mathrm{v}_{*} \times \mathrm{B}_{*}\right]
$$

\section{Conservation of mass}

$$
\nabla_{*} \cdot v_{*}=0
$$

\section{Conservation of charge}

$$
\nabla_{*} \cdot \mathrm{j}_{*}=0
$$

Energy equation

$$
\kappa_{*} \nabla_{*}^{2} \mathrm{~T}_{*}=\left(\mathrm{v}_{*} \cdot \nabla_{*}\right) \mathrm{T}_{*}+\frac{\partial \mathrm{T}_{*}}{\partial \mathrm{t}_{*}}
$$

Where $t_{*}$ is time, $\hat{\mathbf{e}}_{g}$ is the unit vector in the direction of gravity, and $g$. is the gravitational acceleration.

The normalization of the problem can be accomplished in several ways depending on the effect studied. We are mainly concerned with convective heat transfer in sufficiently fast flowing fluids. Therefore, similar to the duct flows, it is assumed that the following quantities are known:

- $a_{*}$, the characteristic length, e.g. film thickness, or drop/jet radius,

- $v_{0 *}$, the characteristic velocity, e.g. the average fluid velocity at the nozzle exit,

- $B_{0 *}$, the characteristic value of the external magnetic field,

- $\Delta T_{*}$, the characteristic temperature difference.

Then the fluid velocity, the magnetic field, the electric current density, the electric potential, the pressure, the temperature, and time are normalized by $\nu_{0 *}, B_{0 *}, \sigma * v_{0 *} B_{0 *}$, $\mathrm{a}_{*} \mathrm{v}_{0 *} \mathrm{~B}_{0 *}, \mathrm{a}_{*} \sigma_{*} \mathrm{v}_{0 *} \mathrm{~B}_{0 *}{ }^{2}, \Delta T_{*}$, and $a_{*} / v_{0 *}$, respectively.

Introducing the dimensionless quantities into Eqs. (1)-(5) gives the dimensionless equations:

$$
\begin{gathered}
H a^{-2} \nabla^{2} v+j \times B=\nabla p+(F r N)^{-1} \hat{e}_{g}+N^{-1}\left\{(v \cdot \nabla) v+\frac{\partial v}{\partial t}\right\} \\
j=-\nabla \phi+v \times B \\
\nabla \cdot v=0,
\end{gathered}
$$




$$
\begin{gathered}
\nabla \cdot \mathrm{j}=0, \\
\nabla^{2} \mathrm{~T}=\operatorname{Pe}(\mathrm{v} \cdot \nabla) \mathrm{T}+\operatorname{Pe} \frac{\partial \mathrm{T}}{\partial \mathrm{t}},
\end{gathered}
$$

where $\mathrm{Ha}, \mathrm{Fr}, \mathrm{Pe}$, and $\mathrm{N}$, are the Hartmann, Froude and Peclet numbers, and the interaction parameter, respectively. They are defined in Sec. 2.4 .

\subsection{Boundary conditions at the solid walls}

The boundary conditions on the solid walls are

- no-slip condition

$$
\mathbf{v}=0
$$

- thin-wall condition

$$
\mathrm{j} \cdot \mathrm{n}_{\mathrm{w}}=\mathrm{c} \nabla_{\mathrm{w}}^{2} \phi,
$$

where $c$ is the wall conductance ratio; $\mathbf{n}_{w}$ is the normal unit vector to the wall, into the fluid; $\nabla_{w}^{2}$ is the Laplace operator in the plane of the wall.

\subsection{Boundary conditions at the free surface}

Suppose that the free surface is given by the equation $H(x, y, z, t)=0$, where $(x, y, z)$ are Cartesian co-ordinates. At the free surface the conditions are:

- the kinematics boundary condition

$$
\frac{\partial H}{\partial t}=(v \cdot \nabla) H
$$

- the dynamic boundary condition

$$
\mathrm{S} \cdot \mathrm{n}_{\mathrm{fs}}=\mathrm{Ha}^{-2} \mathrm{Ca}^{-1} \mathrm{R}^{-1} \mathrm{n}_{\mathrm{fs}}
$$

where $S$ is the stress tensor, $\mathbf{n}_{f s}$ is the unit normal vector to the free surface pointing into the fluid, and $R$ is the mean radius of curvature of the free surface. The latter can be expressed in terms of $H$ as follows:

$$
\frac{1}{R}=\nabla \cdot \frac{\nabla H}{\sqrt{1+(\nabla H)^{2}}}
$$

In the absence of thermo capillary convection, the dynamic boundary condition implies no tangential stress on the free surface, while the normal stress is balanced by the surface tension. 
If surface tension effects are important, boundary conditions along the contact lines must be specified. These lines are the boundaries between the fluid, the solid, and the surrounding medium. This is not a trivial matter, however. Even in the flow problems in the absence of the magnetic field there is still a lack of understanding of what these conditions should be [27]. Dynamic contact angles depend not only on the properties of the liquid and solid metals, but on the fluid velocity in the vicinity of the contact line as well, and may exhibit a hysteresis. The simplest approach is to specify the static contact angles, but it is important to realise that this may not be fully justified.

\subsection{Dimensionless parameters}

Now we consider important dimensionless parameters. Some of them are present in equations (1a)-(5a) and the boundary conditions (7) and (9). The others are more important if different normalization is used. Their typical values for $a_{*}=5 \mathrm{~mm}, B_{0 *}=10 \mathrm{~T}$, and $v_{0 *}=1$ $\mathrm{m} / \mathrm{s}$ are given in Table 2.2. The parameters are:

$\mathrm{Ha}=\mathrm{B}_{0_{*}} \mathrm{a}_{*} \sqrt{\sigma_{*} / \rho_{*} v_{*}}$, the Hartmann number, which characterises the ratio between the electromagnetic and viscous forces. The Hartmann number is sufficiently high for all the liquid metals concerned. Therefore, viscous effects are expected to be confined to thin boundary layers.

$\operatorname{Re}=a_{*} v_{0 *} / v_{*}, \quad$ the Reynolds number, which characterises the ratio of the inertial to viscous forces. The Reynolds number differs by an order of magnitude for $\mathrm{Hg}$ and $\mathrm{Li}$, respectively.

$\mathrm{N}=\sigma_{*} \mathrm{a}_{*} \mathrm{~B}_{0 *}^{2} / \rho_{*} \mathrm{v}_{0^{*}}=\mathrm{Ha}^{2} / \mathrm{Re}$, the interaction parameter, which characterises the ratio of the electromagnetic to inertial forces. It differs by two orders of magnitude for $\mathrm{Hg}$ and $\mathrm{Li}$. For $\mathrm{Li}$, parameters $\mathrm{Ha}$, Re, and $N$ are of the same order of magnitude. If no jets are present within the flow, inertial effects are not expected to be significant [30], [31]. For Hg the inertial effects would dominate, while $\mathrm{Ga}$ represents an intermediate case.

$c=\sigma_{w *} h_{w *} / \sigma_{*} a_{*}$, the wall conductance ratio, which characterises the ratio of the electrical conductance of the wall to that of the fluid; $\sigma_{w *}, h_{w *}$ are the electrical conductivity and thickness of the wall, respectively. In ALPS the walls are supposed to be electrically insulating, so that $c=0$. 
$\mathrm{Pe}=\mathrm{a}_{*} \mathrm{v}_{0 *} / \mathrm{K}_{*}$, the Peclet number, which characterises the ratio of convective and conductive heat transfer.

Fr $=v_{0 *}^{2} / a_{*} g_{*}$, the Froude number, which characterises the ratio of the inertial to gravity forces. The Froude number is independent of the material properties, and is equal to 20 for the case considered here. This means that inertial forces prevail over gravitational ones. They become of the same order when velocity reduces to about $25 \mathrm{~cm} / \mathrm{s}$.

$\operatorname{FrN}=\sigma_{*} v_{0 *} B_{0 *}^{2} / \rho_{*} g_{*}$, the product in Eq. (1a), which characterises the ratio of the electromagnetic to the gravity forces. Since $N$ is sufficiently high, $M H D$ interaction significantly reduces the importance of gravity. The normalized gravity term in Eq. (1a) is proportional to $B_{0 *}^{-2}$. In certain problems, such as the high-speed free jet (sufficiently far away from the receiving plate), gravity becomes negligible.

$\mathrm{Ca}=\rho_{*} \nu_{*} v_{0 *} / \gamma_{*}$, the capillary number, which characterises the importance of viscous with respect to surface tension forces in distorting the interface. If the capillary number is small, viscous forces are not important in this respect. For liquid metals $\mathrm{Ca} \ll 1$. However, as follows from the boundary condition (9) it is not the capillary number that is important, but the product $\mathrm{Ha}^{2} \mathrm{Ca}$.

$\mathrm{Ha}^{2} \mathrm{Ca}=\sigma_{*} \mathrm{a}_{*}{ }^{2} \mathrm{v}_{0 *} \mathrm{~B}_{0 *}^{2} / \gamma_{*}$, he parameter in Eq. (9), which characterises the importance of electromagnetic forces with respect to surface tension forces in distorting the interface. Despite the fact that $\mathrm{Ca}^{-} \ll 1$, parameter $H a^{2} \mathrm{Ca} \gg 1$, so that the electromagnetic forces can easily distort the interface.

$\mathrm{We}=\mathrm{ReCa}=\rho_{*} v_{0 *}^{2} a_{*} / \gamma_{*}$, the Weber number, which characterises the relative effect of inertia with respect to surface tension. The Weber number is usually used in inertia-dominated problems, since is does not depend on the viscosity of the fluid.

Bo $=\rho_{*} g_{*} a_{*}^{2} / \gamma_{*}$, the Bond number, which characterises the ratio of gravitational to surface tension forces. The Bond number is important in problems with (quasi-) static free surface, such as the one considered in [32]. If the Bond number is small, the surface tension forces dominate the 
gravitational ones, and the free surface tends to have a constant curvature. If $B o$ is large, gravity is the dominant force, and the freesurface tends to become flat. Among the liquid metals considered in the Table 2.2, Bo is smallest for $\mathrm{Li}$, and highest for $\mathrm{Hg}$. Liquid metals commonly used in laboratory experiments, such as mercury or indiumgallium-tin, have the Bond number which is higher than that of lithium by an order of magnitude. The Bond number for gallium is of the same order as that for indium-gallium-tin.

The discussion of flow regimes and the implications on the flow modelling at fusion relevant conditions will be given in Sec. 7. 


\section{Liquid-Metal Film Flow}

Most theoretical and experimental MHD studies of free-surface flows have been performed for liquid metal films. MHD issues related to the film flow are listed in Table 3.1. Tables 3.2 and 3.3 summarize the parameters achieved and the number of data points reported in the main experiments published to date.

Consider a liquid metal film flowing in a chute (figure 3.1). The distance between chute's sidewalls is $2 b$.. The length of the chute is denoted by $L_{*}$; it is the distance between the orifice and the collector. A solid backing plate is located at $z=0$ and is inclined at an angle $\alpha$ to the horizon. In the diverter the magnetic field, applied in the $(y, z)$-plane at an angle $\beta$ to the horizon, is parallel, or almost parallel to the free surface. The free surface is defined by the dimensionless equation $H \equiv z-h(x, y, t)=0$. It is normalized by the characteristic value of the film thickness, $a_{0}$.

For a film flowing in a chute the flow rate, $q_{*}$, is usually a given quantity, while the average fluid velocity is expressed as follows:

$$
v_{0 *}=q_{*} /\left(2 a_{*} b_{*}\right) \text {. }
$$

Since the sidewalls of the chute are the Hartmann walls, it is convenient to define the Hartmann number using $b_{*}$ as the characteristic length. The Hartmann number, $H a_{b}$, defined in this way, is independent of the film thickness, and is related to $\mathrm{Ha}$ as follows: $\mathrm{Ha}_{b}=b \mathrm{Ha}$. Since $b_{\bullet} \gg a_{\bullet}$ (see Table 3.2), then. $b \gg>1$, and thus $H a_{b} \gg>H a$. .

\subsection{Fully developed flows}

Consider first a fully developed flow ( $h=$ constant, $\partial / \partial x=0$ ) in a coplanar magnetic field, i.e. for $\beta=0$. This means that we are dealing with the region sufficiently far from the orifice.

If the magnetic field is sufficiently strong $\left(H a_{b}>1\right.$ and $\left.\sqrt{H a_{b}}>b / h\right)$, three main type of flow sub regions are expected (figure 3.2):

- the core $C$

- the Hartmann layers $H$ of thickness $O\left(H a_{b}^{-1}\right)$; they are at the side walls $y= \pm b$; 
- the parallel layers $S I$ and $S 2$ of thickness $O\left(H a_{b}{ }^{-1 / 2}\right)$; they are at the free surface $z=h$ and at the backing plate $z=0$, respectively.

If the magnetic field is not sufficiently strong, i.e. $\sqrt{H a_{b}}=O(b / h)$, the whole flow domain is occupied by a single parallel layer (see the discussion below).

By analogy with the duct flows with thin conducting walls one may expect the formation of the high-velocity jets of magnitude $O\left(\mathrm{Ha}_{b}{ }^{1 / 2}\right)$ in the parallel layers both at the backing plate and at the free surface, depending on the wall conductance ratios of the sidewalls and the backing plate. The paths of the electric currents are shown in figure 3.2 ; they are similar to the corresponding duct-flow problem.

Perhaps the most significant theoretical result for liquid metal film flows has been obtained by Shishko [55]. He used a Galerkin method with two basic functions in the $y$ direction, the parabola and the Hartmann profile, to approximate the velocity profile along the magnetic field lines. The method is not especially accurate, because of low number of the trial functions. Nevertheless, it is useful to demonstrate basic effects.

\subsubsection{Insulating sidewalls}

Figure 3.3 from [55] shows velocity profiles in a plane $(x, z)$, i.e. in a plane transverse to the magnetic field. The flow features may be summarized as follows. At a sufficiently high Hartmann number, the velocity in the core tends to being constant (fig. 3.3c). It is interesting to note, however, that even for $H a_{b}=10,000$ (fig. 3.3a) the core has not been formed yet. As has been discussed above, the reason is that the magnetic field is still not strong enough to dominate viscous forces. Indeed, parallel layers $S 1$ and $S 2$ have the thickness $O\left(H a_{b}^{-1 / 2}\right)$, roughly 0.01 . Since $h / b=0.0104$, they occupy the whole flow domain. In contrast, for $H a_{b}=$ 40,000 (fig. 3.3c), the core and the parallel layers are clearly distinct, since $\mathrm{Ha}_{b}{ }^{-1 / 2}=0.005$, while $h / b=0.0321$.

In a strong magnetic field the core velocity is equal to the average one. The maximum of the free-surface velocity is ${ }^{\dagger}$

$$
\mathrm{v}_{\text {free.surf.max. }} \approx 1.84 \mathrm{v}_{\text {core }},
$$

i.e. roughly double the core velocity. It remains $O(1)$ as $H a_{b} \rightarrow \infty$, i.e. there is no highvelocity jet at the free surface.

\footnotetext{
${ }^{t}$ A more precise value is $v_{\text {freesurf } \text { max. }} \approx 1.73 v_{\text {core }}$, obtained numerically in [37]
} 
In figure 3.4 the dependence of the film thickness and of the average velocity on the Hartmann number is shown. At high values of the Hartmann number, i.e. when the flow splits into the core and the parallel layers, the average velocity becomes independent of the flow rate, and the film thickness becomes proportional to $H a_{b}$.

Further calculations in [55] showed that the effect of the conductivity of the backing plate on both local and global flow characteristics is insignificant. This is analogous to the duct flow, and can be understood by analysing the current paths in figure 3.2.

Before the study [55] appeared, a flow model was developed based on the method of "averaging" [1]. The essence of this model is that the velocity profile in the magnetic field direction is assumed to be of Hartmann type, i.e. flat core, and exponential boundary layers at the sidewalls. This profile is assumed for the whole flow region, including the parallel layers, where a different velocity profile in the field direction is expected. Owing to its simplicity such a flow model has been applied before for MHD duct flows, see e.g. [23].

A simple free surface experiment with insulating walls which compared the results with this "averaging" approach was also reported in [1]. The experiment parameters are given in detail in Tables 3.2 and 3.3. Briefly, the experiment was a horizontal, insulating walled chute using Ga-In-Sn. Results reported were nine centerline film thickness measurements along the length of the chute at two B-fields of $0.5 \mathrm{~T}$ and $1.25 \mathrm{~T}$ (Hartmann numbers, $\mathrm{Ha}$, of 500 and 1240 , respectively). The agreement obtained, for this flow field parameter, was quite good. No other data were reported. Note that this and all other experiments examined in Tables 3.2 and 3.3 are 30-300 times too low in Hartmann number, compared to ITER conditions, and 2-3 orders of magnitude too low in MHD interaction parameter.

Although the averaging model is capable of predicting some flow features, it fails to reveal the other important ones. In the liquid film flow context it fails to predict such an important feature as hysteresis of the film thickness [55] discussed below. Neither it is valid for an inclined field. Therefore, it is not recommended for further development.

\subsubsection{Conducting sidewalls}

The case of electrically conducting side walls, also considered in [55], is more interesting. Two flow regimes are possible, fast and slow. 
For a thin film, i.e. for $h / b=O\left(H a_{b}^{-1 / 2}\right)$, parallel layers $S l$ and $S 2$ merge. The core disappears, and there are no distinct jets in the parallel layers (figure 3.5a). However, since the film thickness is $O\left(H a_{b}^{-1 / 2}\right)$, the average velocity itself is high, $O\left(H a_{b}^{1 / 2}\right)$. This flow regime is called fast.

In a thick film, for $h / b \gg H a_{b}^{-1 / 2}$, the parallel layers $S 1$ and $S 2$ split, and the core develops. Two jets are present in the parallel layers, which carry most of the volume flux (figure 3.5b). The mechanism for the appearance of the jets is identical to that in the duct flows. Since the film is thick, the flow regime is called slow.

This terminology "slow" and "fast" is somewhat ambiguous, since the "fast" regime prevails at low flow rates, and "slow" regime - at high. It becomes clearer, however, when the variation of the film thickness with the flow rate is considered (figure 3.6). There is a range of the flow rate variation when two regimes may coexist. This range is bounded by two 'critical' values of the flow rate, $q_{c r 1}$ and $q_{c r 2}$. Between these two values the film thickness may assume three values, corresponding to fast and slow regimes and the third one, which cannot be realised in practice. The reason for such a behaviour is that in this range of flow-rate variation, the hydraulic resistance is the same for three different flow patterns or values of the film thickness. It is clear that the transition from the fast to the slow regime and back occurs abruptly when the flow rate varies, exhibiting a hysteresis. The ratio $h / b$ in the slow regime is $\sim B_{0 *}^{2}$, while the average velocity decreases as $B_{0 *}^{-2}$ as $B_{0 *}$ increases.

The experimental work reported in [39], in a conducting wall chute, with a coplanar magnetic field, presented axial profiles of centerline film thickness for $H a=137$ and $H a=200$. The results were too limited in number, and too far away from ITER-relevant conditions to be useful in the present situation.

\subsubsection{Other studies}

Walker [59], [60] developed asymptotic solutions for fully developed flow in a coplanar field for the following cases:

- insulating sidewalls, insulating backing plate

- perfectly conducting sidewalls, perfectly conducting backing plate

- perfectly conducting sidewalls, insulating backing plate.

The results for the velocity profiles are qualitatively similar to those described above. Although these papers appeared before [55], no hysteresis in the film thickness has been noticed. 
Numerical, finite-difference studies of the film flow in a coplanar field include [22], [36], [37], which confirm the results of [55] and asymptotic studies [59], [60]. Overall, the fully developed flow in a coplanar field is well understood.

\subsection{Inclination of the field}

The effect of the inclination of the magnetic field to the free surface in the fully developed liquid metal film flow has been investigated theoretically in [22], [36], [37], [40].

When $\beta \neq 0$, three situations are possible depending on the film ratio $h / b$, see [36]. They are shown in figures 3.7-3.9 for a fixed field inclination, $\beta$ and for three different values of $h / b$. This situation is analogous to that in a duct flow, see [4], [33], [34].

When $\beta$ increases, parallel layers $S 1$ and $S 2$ detach from the free surface and the backing plate. They follow two magnetic field lines, which cross the bottom-left corner of the chute and the opposite free-surface corner. The parallel layers separate two or three cores from each other. Since there is a non-zero component of a magnetic field at all the solid walls and the free surface, Hartmann layers are formed there (not shown in figs. 3.7-3.9). Decreasing thickness leads to the shifting the parallel layer $S 1$ down, together with the free surface, towards the other parallel layer $S 2$. The central core $C 1$ shrinks, while the other two cores, $C 2$ and $C 3$, grow in size relative to $C 1$. For $h / b=O(2 \tan \beta)$ layers $S I$ and $S 2$ merge, and the core $C I$ disappears (fig. 3.8). Further decrease in $h$ leads to the interchange between the layers $S 1$ and $S 2$, while the central core $C I$ reappears again (fig. 3.9 ).

Velocity profiles and electric current lines for insulating or electrically conducting side walls for the three flow regimes are shown in figs. 3.10 and 3.11 , respectively. It is clear that for the conducting sidewalls, the high-velocity jet at the free surface, which carries virtually all the volume flux, becomes severely distorted (figs. $3.11 \mathrm{~b}, \mathrm{c}$ ). The resulting velocity profiles are highly undesirable. For fusion-relevant inclination angles the hysteresis in the film thickness discovered for a coplanar field remains valid [37].

In [6] and [25], film thickness distributions across the width of the chute were measured for inclined fields of $\beta=7^{\circ}$ and $\beta=12^{\circ}$, respectively. In [25], a surface potential distribution was also presented. The skew shape of these distributions was in qualitative agreement with the above discussion, though in dimensionless parameter space $(H a, N),[6]$ and [25] are 2-3 orders of magnitude away from ITER conditions. 


\subsection{Three-dimensional effects and film stability}

Although the fully developed flow in both coplanar and inclined field is well understood, the question remains whether this flow can be realized in practice. The experiments [6], [7], [24] suggest that this may not be the case. The experiments in [6] and [7] reveal a very nonuniform film thickness over the cross-section of the chute with maximum at the sidewalls. This maximum may exceed the film thickness at the center of the chute by a factor of 2 [6] or even 5 [7]. In one of the experiments [7] two flow regimes have been observed simultaneously: slow one at the sidewalls, and fast in the core. The flow pattern was very complicated, exhibiting "soliton-like effects", or "the dolphins" [7], at the sidewalls. The origin of these effects is unclear. Possible triggers may be the three-dimensional effects (exit from the orifice, spatially varying field, or effective decreasing of gravity at the sidewalls owing to 3-D currents), wet ability of the chute's walls, finite dimensions of the meniscus (see Sec. 3.5), or flow instability. For an inclined field the film thickness never becomes constant over a cross-section, which means that the development length is very high.

Another free surface experimental study in an insulated chute was presented in [51]. The study focused on the 3D effects of the flow entering and exiting the magnetic field. In that case, because of the unique geometry, the results reported are not entirely relevant for the present application. The chute was quite long, $3.5 \mathrm{~m}$, and the magnet, with pole pieces $0.35 \mathrm{~m}$ long, was located $2 \mathrm{~m}$ downstream of the inlet of the chute. Thus, there was no means of controlling the initial height of the film, and the $\mathrm{MHD}$ flow thus obtained was dominated by $3 \mathrm{D}$ effects at the inlet and exit of the magnetic field, which are fundamentally different from those anticipated here. In film flow free surface plasma facing devices envisioned to date, the flow issues from a forming nozzle inside the magnetic field, and the 3D effects do not come mainly from magnetic field gradients.

Concerning film stability, it has been observed in [7], as well as in other experiments, that the magnetic field stabilizes the free surface at the centre of the chute. One of such experiments is found in [57], which was performed in connection with the present fusionrelated applications. In that work, an open channel with insulating side walls was used to measure centerline film thickness along the downstream direction. Data were presented for two cases, with and without a forming nozzle. No theory was available with which to compare the results. The main observation was a significant MHD interaction at $\mathrm{Fr} \sim 1700$ and $\mathrm{Ha} \sim$ 1500 which resulted in eliminating a large wave at $2<x / b<4$.

All experimental papers papers listed in Tables 3.2 and 3.3, except [1] and [51], report a significant effect of the magnetic field in reducing both large scale and small scale surface waves, disturbances, and instabilities. Measurements of wave amplitudes with and without the 
magnetic field, presented in [6] for a Hartmann number of about 900 , show reductions in wave amplitude that range from a factor of two, to their complete elimination near the side walls having a relative conductivity $c \sim 0.02$.

Theoretical results for film stability [2], [20], [26], [41] are based on a quasi-onedimensional models, and thus cannot be considered satisfactory. It should be noted that even for duct flows the question of flow stability is still unresolved. Since this issue is very important, it is recommended that it is treated as a priority for theoretical considerations.

Other theoretical and experimental studies of film flows include [3], [12], [16], [17], [42], [44]-[48], [53], [54], [57].

\subsection{Wettability of solid walls and rivulets}

Many authors [6], [7], [24], [57] report that a sufficiently thin film will break-up into rivulets if wettability of the surface cannot be insured. For a film of any thickness, the liquid metal is not in contact with the unwetted sidewalls. This may lead to the burn-out of the sidewalls. Therefore, for a film diverter one must ensure good wettability of the walls through the lifetime of the diverter. Insulating coatings, if they are used, should have the same property.

An important experiment on an In-Ga-Sn film flow has been performed by Lebedev, Fokin and Yakovlev [24]. Two different situations have been studied: flow on a solid backing plate, or flow on a porous backing plate. We discuss the first case here; the second case is beyond the scope of this paper.

The main aim of the experiments on a solid backing plate was to determine the effect of wettability and electrical conductivity of the plate on the high-speed film flow. The test section represented an inclined chute $\left(\alpha \leq 15^{\circ}\right)$ in a magnetic field inclined to the free surface at an angle $\beta \leq 12^{\circ}$. The length of the chute was $0.5 \mathrm{~m}$, and the width $0.025 \mathrm{~m}$. The film thickness was varied in the range of $a_{0}=0.5-5 \mathrm{~mm}$ using a slit. Materials of different wettability and the wall conductance were used for both the backing plate and the sidewalls. The parameters (defined with the values of the average velocity at the exit from the slit and the film thickness) varied in the following range:

$$
0.5<F r<1,000, \quad 2,000<\operatorname{Re}<65,000, \quad 0<H a<500 \text {. }
$$


The first important observation is related to the non-wetted electrically insulating backing plate and sidewalls. For thin films $\left(1<\mathrm{a}_{*}<5, \mathrm{~mm}\right)$, in the range $B o \leq 4$ the fluid tends to form rivulets right at the entrance from the slit, leaving part of the backing plate dry. This regime is characteristic for a wide range of the fluid velocity variation $\left(0.15<\mathrm{v}_{0 *}<4.5\right.$, $\mathrm{m} / \mathrm{s})$. The magnetic field $\left(B_{0 *} \leq \mathrm{IT}\right)$ does not have an effect on the shape of the rivulets. However, it does suppress disturbances of the free surface. An inclined magnetic field has a similar effect on the flow.

For higher velocities the fluid tends to cover the backing plate owing to inertial effects. For thicker films $\left(a_{*}>6 \mathrm{~mm}\right.$ ), and for $\mathrm{Bo} \geq 4$ full or partial (up to $90 \%$ ) filling of the chute occurs. In the case of complete filling of the chute a hydraulic jump occurs within the flow region.

Velocity profiles have been measured for fully covered backing plate, and for $a_{*} \approx 6 \mathrm{~mm}$, Bo $>4$. Away from the slit, the fluid detaches from the sidewalls, while the film thickness increases. The most uniform filling of the chute can be obtained for high film thickness and low velocities.

If both the backing plate and the sidewalls are wetted and well conducting, the fluid covers the backing plate completely in all the flow regimes. If the film is thin $\left(a_{*}<2 \mathrm{~mm}\right)$, the fluid is not in contact with the sidewalls, making electromagnetic interaction weak. If the film is thick $\left(a_{*}>3 \mathrm{~mm}\right)$ the increase in the magnetic field strength leads to the increase of the thickness of the film along the flow, leading to a hydraulic jump.

The most stable flow configuration has been observed in a chute with wetted, weakly conducting backing plate and non-wetted insulating sidewalls. At high flow velocities the homogenization of the free surface both along and across the flow direction has been observed.

As has been discussed above, in certain flow regimes the fluid does not cover the backing plate completely. Then one or several rivulets are formed. Molokov \& Reed [32] studied theoretically the fully developed flow in a rivulet in either transverse $\left(\beta=\frac{1}{2} \pi\right)$ or horizontal $(\beta=0)$ magnetic fields at high values of the Hartmann number. The flow is driven by gravity only, so that the characteristic velocity is $v_{0_{*}}=\rho_{*} g_{*} /\left(\sigma_{*} B_{0_{*}}^{2}\right)$. In the fully developed regime the magnetic field does not affect the shape of the rivulet, which is determined by the balance of gravity and surface tension forces.

When the fluid flows down an inclined plane in a transverse magnetic field, an $O(1)$ electric current is induced initially in the negative $y$-direction. This component of current interacts with the magnetic field to produce the Lorentz force, which balances gravity in the 
core. The core electric current must vanish at the free surface, and as a result, the current lines repeat the shape of the free surface (fig. 3.12a). The electric current completes its path in the Hartmann layer at the plate, where it is $O(H a)$ owing to current conservation. While passing through the Hartmann layer, the current induces an $O(H a)$ electric potential difference in both the layer, and the core, which must be balanced by the electromotive force $(v \hat{x}) \times e_{B}$. This leads to the $O(H a)$ velocity in the core. Fig. 3.12b shows velocity profiles at different positions $y=$ const. To the leading order, $O(H a)$, the profile repeats the shape of the rivulet's cross-section, similar to the flow in insulating ducts. The $O(1)$-correction to the velocity profile leads to a slight linear variation with $z$ in the core. There is no Hartmann layer at the free surface to the leading order. The Hartmann layer appears in the next, $O(1)$ approximation. The reason for its appearance is that the $O(\mathrm{Ha})$-velocity is a function of $y$ only, and this leads to a non-zero, $O(1)$ traction at the free surface. This traction is compensated by the exponential variation of the velocity in the Hartmann layer, which is evident in fig. 3.12b. In dimensional terms both the local and average fluid velocities are proportional to $\mathrm{B}_{0 *}^{-1}$.

In the case of the parallel magnetic field, the magnetic field lines do not cross the solid boundary, the velocity in the core turns out to be $O(\mathrm{Ha})$ higher than for the transverse field, i.e. it is independent of the magnetic field for sufficiently high field. The viscous force is of the same order as the electromagnetic one. The electric current lines are shown in fig. 3.13a. The role of the magnetic field is to "straighten" the velocity profiles in the horizontal direction. The latter may be described by a single curve for all values of $y$, shown in fig. 3.13b. The zerotraction conditions at the free surface are satisfied in the lower-order Hartmann layers. It is important to note that in contrast to the transverse field, the flow in the bulk of the cross-section is viscous. Therefore, to the leading order the "core" occupies the whole cross-section.

For both field directions (i) the velocity does not vary along the magnetic field lines; (ii) there is a lower-order Hartmann layer at the free surface, which is formed to relax traction at the free surface, produced by the core flow.

Three-dimensional flows in rivulets in a nonuniform, transverse magnetic field have been studied by Oshima et al. [49], [52] both theoretically and experimentally. Their theoretical analysis resulted in a system of two ordinary, nonlinear differential equations for the height and the width of the rivulet as a function of the streamwise co-ordinate. Several simplifying assumptions have been made concerning both the shape of the rivulet and the flow pattern, some of which were not fully justified. Nevertheless, their theoretical results are generally in qualitative agreement with the experiments. If the rivulet flows into the magnetic field, it narrows, while its height increases. If the rivulet flows out of the magnetic field, it widens, while its height decreases. In both cases the rivulet tends to recover its initial shape once the non-uniform region is passed. 


\subsection{The meniscus}

An important characteristic of the surface tension effects is the capillary length

$$
\mathrm{l}_{\mathrm{c}^{*}}=\sqrt{2 \gamma_{*} / \rho_{*} \mathrm{~g}_{*}},
$$

which gives the approximate size of the meniscus (figure 3.14). The capillary length for all liquid metals in Table 2.1 is sufficiently high. For $\mathrm{Ga}$, for example, it roughly equals the characteristic length, $a_{*}$, and is much higher than the thickness of either parallel or Hartmann layers. This means that for a film meniscus effects may be very important, especially for a three-dimensional flow. This effect has not been investigated theoretically.

\subsection{Plasma wind}

The effect of plasma wind on the uniformity of the film thickness is another factor that needs to be taken into account. It may be considerable, and may lead to the film disruption [38].

\subsection{The effect of imperfect insulation of coatings}

If cracks in the coating appear either on the backing plate or on one of the sidewalls, the most likely effect is the appearance of a dry spot exposed to high heat flux. Thus the requirements to the coatings should be even higher than for the liquid metal blankets, and this fact needs to be taken into account when viability of coating is discussed. The effect of imperfect insulation of coatings in the context of liquid metal blankets is discussed in [8], [9]. 


\section{Liquid-metal jets}

One of the most important advantages of a jet flow with respect to the film flow is that a jet interacts very weakly with the uniform, transverse magnetic field in the steady-state regime. MHD issues for liquid metal jets are summarized in Table 4.1.

\subsection{Three-dimensional effects}

These effects may affect the velocity profile of the jet, and thus heat tranifer characteristics. They may also affect stability of the jet. Although no detailed studies exist, there are experimental observations in [7] of the jet emanating from a nozzle in a horizontal field, see fig. 4.2. Visual observations could find no significant effect on the jet velocity profile, but the continuous length of the jet was increased by the presence of a horizontal field.

The experiments in [7] have been performed with In-Ga-Sn in a transverse magnetic field of up to 3.5T. The magnetic field was strongly nonuniform with gradient of $12-15 \mathrm{~T} / \mathrm{m}$. The jets emanated from $10-30 \mathrm{~mm}$ long electrically insulating nozzles of 1-3 mm diameter. The velocity of the jets was up to $2 \mathrm{~m} / \mathrm{s}$. The application of a strong magnetic field leads to both a stabilization of jets, which looked like taut strings, and to an increase in the length of the continuous part of the jet. It is hypothesised in [7] that the stabilization of the jets occurs owing to the suppression of disturbances inside the nozzle.

Another experiment with the jets, presented in [7], has been performed with In-Ga-Sn in a solenoid magnet with either flat, slot-like jet (or a sheet), or a row of 25 jets situated in the plane of the field. The flat jet emanated from a slit of $100 \mathrm{~mm}$ wide and $2 \mathrm{~mm}$ thick and was also oriented in the plane of the field. The nozzles for the system of jets had a diameter of $2 \mathrm{~mm}$, while the distance between the nozzle centers was $4 \mathrm{~mm}$. Both the nozzles and the slit were made of an insulating material. The jets were falling on an inclined, electrically conducting backing plate. Only visual observations were reported. The photographs of the jets are presented in fig. 4.1. It has been observed that in the applied magnetic field the jets were thicker, while the splashing of the liquid metal at the impact with the backing plate was significantly damped. Also the magnetic field straightened the jets and made them parallel to each other. At $4 \mathrm{~T}$, the backing plate was fully covered with the liquid metal film with mirrorlike, stable surface. 


\subsection{Spatially varying field}

The effect of a nonuniform, transverse magnetic field on a jet has been studied both theoretically and experimentally in [50], though not in the fusion context. It has been shown that the jet tends to flatten in the direction perpendicular to the nonuniform field. Theoretical model was based on the assumption of an inviscid fluid. The effects of gravity in the model had been neglected. Qualitative agreement between the theory and the experiment was sufficiently good, while quantitative agreement was quite poor. This may had been influenced by the fact that in the experiments the jet was horizontal, and the effects of gravity could not be dismissed. This issue is not expected to be a critical one for the diverter. Results reported in [7] on jet behavior in a strongly nonuniform field gradient along the direction of flow, i.e. that the jet was stabilized and that the length of the continuous part of the jet was increased, are somewhat relevant here.

\subsection{Jet stability in a strong transverse magnetic field}

No theoretical results exist for fusion-relevant conditions. However, a transverse field is expected to stabilize the jet. This has been observed in one experiment [7], see fig. 4.1; in the other [50] the stabilizing effect was less pronounced. Theoretical understanding of the jet stability is essential.

\subsection{Impact of a jet on solid wall or a liquid metal surface}

This issue is important because of possible splashes of liquid metal. No splashes were observed in the experiment [7] in magnetic fields $B_{0^{*}}>2.5 \mathrm{~T}$, see fig.4.1, which is an important result. Understanding of the phenomenon is insufficient owing to the lack of theory. 


\section{Liquid-metal Drops}

Similar to the jet flow, in the steady-state regime, drops practically do not interact with the uniform magnetic field. MHD issues for liquid metal drops are summarized in Table 5.1.

\subsection{Jet/film atomizer}

If a cloud of drops is employed for the diverter, the most important issue is how to enforce atomization of a jet or a film within a 5-10T magnetic field. Although not studied theoretically, the effect of a transverse magnetic field is to stabilize the jet. Therefore, capillary force alone will not be sufficient to disintegrate a jet/film.

One method of producing drops has been presented in [58], and in greater detail in [11] (see also [29] and fig. 5.1). It is based on the application of an AC current that facilitates the jet disintegration. In [58], an electromagnetic jet-droplet flow generator device was used to form a jet-droplet curtain with its active zone directly in the tokamak discharge chamber of the T-3M tokamak test facility. A uniformly spaced droplet flow was produced as the result of the interaction between an AC current within the droplet generator and the quasi-steady $1 \mathrm{~T}$ toroidal magnetic field of the tokamak. The liquid metal flow of $2-4 \mathrm{~mm}$ diameter droplets consisted of 17 jets arranged in two rows with $4 \mathrm{~mm}$ pitch. The droplet flow moved vertically downwards across the toroidal magnetic field with a velocity of $2-5 \mathrm{~m} / \mathrm{s}$. With respect to the plasma, the droplet curtain served as a rail limiter at a depth of $15-20 \mathrm{~mm}$ into the plasma column. Data collected from several facilities were reported in [11] on parameters which affect the formation of the droplets such as, current and frequency of the AC excitation, diameter and length-todiameter ratio of the jet orifices, and applied magnetic fields ranging from $0.5-2.5 \mathrm{~T}$. No results were reported, however, on the MHD behavior of the droplets within the magnetic field, once they were formed. Muraviev' reported that sometimes during the atomization experiments [29] violent vibrations have been observed. Whether such a system may be allowed into a tokamak is an important technical question.

\subsection{Spatially varying field}

Since the magnetic field in the diverter area has a rather complicated structure, the drop, on its path from the atomizer to the receiving plate, will move in a (maybe slightly) varying

\footnotetext{
' private communication, Junc, 1999
} 
magnetic field. This may lead to the deviation of a drop from its original path or change in its shape. Muraviev [43] estimated this effect for solid particles, thus neglecting associated hydrodynamic phenomena.

Muraviev showed that a particle moving in a nonuniform magnetic field will always slow down. Deviation of the particle trajectory will occur if the angle between the particle velocity and the vector of the magnetic field variation do not coincide. The varying magnetic field can also induce an angular momentum, and this leads to the induced rotation of the particle. The combined "external" effect that leads to the change in the particle velocity is characterized by Muraviev by the parameter

$$
\mathrm{M}_{\mathrm{e}}=\left|\frac{\Delta \mathrm{v}}{\mathrm{v}}\right|,
$$

where $\Delta v$ is the increment of the particle velocity.

In addition to the external effect, a drop will experience a deformation in a varying field. Estimation of the induced internal stress within a particle shows that the particle will experience contraction or expansion depending on whether it goes into or out of the region of the stronger field. Muraviev characterizes this "inner" effect by the dimensionless factor

$$
M_{i}=\frac{p_{m}+p_{c}}{p_{s}}
$$

where $p_{m}, p_{c}$ and $p_{s}$ are stresses owing to an electromagnetic force, centrifugal force, and surface tension, respectively.

The results for lithium particles in the field of $6 \mathrm{~T}$, varying over a distance $30 \mathrm{~cm}$, are shown in Table 5.2. While the deviation of the particle from the original trajectory is quite small for all cases considered, a fact that has been confirmed experimentally in [15], the deformation can be very significant indeed. This begs the question as to whether internal stresses may lead even to a break-up of the drop into smaller ones. Further theoretical and experimental study of this effect is necessary.

\subsection{Drop stability/oscillations in a strong transverse magnetic field}

After leaving the atomizer, the drop starts its path in a magnetic field having a certain internal initial velocity distribution. The question is how will the flow pattern evolve. Can some oscillations survive and lead to the drop break-up? 
Gailitis [13] considered oscillations of a liquid metal drop in a magnetic field. He neglected both viscous and inertial terms in the momentum equation, and in essence considered an unsteady version of the core-flow equations. These assumptions are justified if the deviations from the spherical shape are small, as has been assumed in the paper. The analytical results show that oscillations may be divided into four different groups. These are oscillations, which are

1. independent of the magnetic field. In this case the motion of fluid is in the plane perpendicular to the magnetic field, and is independent of the field direction. This fact is well-known.

2. damped in weak fields but aperiodic in strong fields. This includes axially symmetric oscillations, which are even functions of the magnetic-field co-ordinate

3. weakly damped in both weak and strong field. This includes axially symmetric modes, which are odd functions of the magnetic-field co-ordinate.

4. totally aperiodic: all other modes

The significance of this investigation is in demonstrating that there several types of oscillations, which may survive in the magnetic field for a very long time. The work is purely theoretical, and no estimate has been made for diverter applications.

\subsection{Impact of a drop on solid wall/shallow liquid metal layer}

This issue is important because of possible splashes of liquid metal. The effect has been studied experimentally in [19] (fig. 5.2). The experiments, which had-a qualitative character, were performed in a horizontal magnetic field of up to $1.33 \mathrm{~T}$ with $\mathrm{In}-\mathrm{Ga}-\mathrm{Sn}$ and mercury. The height of the layer of metal was $1 \mathrm{~cm}$ and higher; drop diameter was $2-3 \mathrm{~mm}$, and velocity was 3-6 m/s. The main result is that the magnetic field significantly changes the nature of the drop impact. It also reduces the time of undulations of the free surface after the impact. However, the diameter of a "crater" seems to be not significantly affected. The impact should have an anisotropic nature due to the preferential direction along the magnetic field lines. This has not been studied in the experiment, and no theoretical results exist. In summary, although the results of the experiment are encouraging, since no significant splashes exist, understanding of the phenomenon is poor. 


\subsection{Thermo capillary convection}

Gailitis \& Gerbeth [14] discussed thermo capillary motions in drops due to one-sided heating in a strong field. This type of convection occurs if the surface tension, $\gamma_{\bullet}$, significantly varies with temperature. They applied a heuristic, analytical, asymptotic method for high values of the Hartmann number. The drop was supposed to have a spherical shape. They estimated that without the magnetic field the velocities in the drops due to thermo capillary effect can reach the values of $\sim 1 \mathrm{~m} / \mathrm{s}$ in a heat flux of $1 \mathrm{MW} / \mathrm{m}^{2}$. This may lead to fragmentation of the droplet. With the magnetic field this value must be reduced by a factor of $\mathrm{Ha}$ on the surface and $\mathrm{Ha}^{2}$ in the bulk of the drop, so they concluded that the effect is too weak. However, the Hartmann number estimated for the drop of $0.5 \mathrm{~mm}$ in radius is about 50 for a field of $5 \mathrm{~T}$, which is not very high. The heat flux is expected to be much higher, $10-15 \mathrm{MW} / \mathrm{m}^{2}$ or even higher. Therefore, the effect may be significant with velocities reaching $1 \mathrm{~m} / \mathrm{s}$; it requires further study. 


\section{Other Effects Common To All Designs}

In this Section we briefly mention three issues that are common to all designs.

The first one is the pressure drop in the supplying/draining systems. This is a duct-flow problem. For the supplying system the pressure drop needs to be acceptable. The draining system should provide adequate removal of the liquid metal, perhaps by gravity force alone. For this purpose insulating coatings may prove to be necessary. However, it depends on a specific diverter design.

The second issue is the effect of time-dependent magnetic fields during plasma disruption. In the event of plasma disruption time dependent magnetic fields may induce global currents within either film- or jet- diverters. This may lead to splashes of the liquid metal and its penetration into the plasma chamber. According to Muraviev (private communication), this effect is very important. However, as far as we know no estimates of the effect exist.

In contrast to film- and jet- flows, where global currents may be induced during plasma disruption, no such currents are possible for drops, since they are isolated from each other and are of small diameter. In general, however, similar to spatially varying fields, time-varying fields may induce forces, which may force the drops out of the diverter region, into the plasma chamber. No studies of this effect exist.

The third issue concerns variation of the electrical conductivity with temperature. This may affect the velocity profile by up to $30 \%$. This is an underdeveloped area, but it is not likely to be important at this stage. 


\section{Discussion And Recommendations}

Concerning liquid metal film diverters, there are several uncertainties that may potentially result in a significant amount of R\&D. These concern stability of the film, uniformity of film thickness owing to inertia, 3-D effects, inclination of the field, plasma wind, etc. Finite conductance of the sidewalls, combined with inclined field, may lead to very undesirable effects. Even in the coplanar field, experimental studies [6], [7] reveal a very nonuniform film thickness over the cross-section with maximum at the sidewalls. The origin of this effect is not fully understood up to now.

Concerning velocity profiles, it seems that only if walls are electrically insulating, velocity profiles are more or less insensitive to the field inclination. This leads to the necessity of insulating coatings. Another question arises then, whether wettability of the coatings by a liquid metal can be sustained for a lifetime of the diverter. If this is not the case, the liquid metal film may turn into rivulets, and dry spots may appear.

For liquid metal jets the number of MHD-related problems is considerably lower. Initial experiments [7] demonstrating stable jets and mirror-like, disturbance-free layer of liquid metal on the receiving plate, are very convincing. Although the liquid metal coatings in the supplying/draining systems are likely to be necessary due to pressure-drop considerations, they will not be in the critical region of a tokamak, and the requirements to such coatings could be not very strict. Major question remains as to how the jets will behave during plasma disruption, but this question is as important for the films.

Similar to jets, drop diverters have few MHD-related problems. The crucial question for drops is how to create them realistically in a tokamak. Also, owing to their small size, they will be vulnerable to evaporation and plasma wind.

Therefore, it is recommended that the jet diverter concept be adopted for ALPS.

Concerning modeling, the analysis of the values of parameters in Table 2.2, and the discussion in Secs. 3-5 suggest that for most liquid metals the electromagnetic force is the dominant factor, but there are situations when viscous and inertial forces are equally important. Since the bulk of the knowledge in modeling of the MHD flows is in the area of the inertialess flows, it is recommended that at the first stage an asymptotic, inertialess flow model is adopted. At the second stage inertial effects and turbulence models could be included. 
For the jet diverter the following issues are considered a priority for theoretical consideration:

- three-dimensional liquid metal jet emanating from the nozzle and falling on either a liquid metal surface or an inclined solid backing plate in a transverse field, - $\quad$ stability of a liquid metal jet in a transverse magnetic field.

Concerning the experimental program, several important qualitative experiments for free surface flows have been performed. However, from Table 3.2 follows that the actual number of data points reported on MHD flows is greatly inadequate to form a basis for designing, analyzing, or testing models of fusion-relevant devices. From Table 3.3, it follows that the experimental conditions achieved to date are simply too far from the fusion relevant parameter space to be of any practical use in PFC engineering; the available results, at most, affirm our intuitive notions of the effect of magnetic fields on liquid metal flows in general. For jet flow the knowledge is even less extensive. Therefore, a systematic experimental program to gather a quantitative information is required. 


\section{REFERENCES}

1. Aitov, T.N., Ivanov, A.B., Tananaev, A.V., 1987, Flow of a liquid metal in a chute in a coplanar magnetic field, Magnetohydrodynamics, 23, 91-95.

2. Aitov, T.N., Kirillina, E.M., Tananaev, A.V., 1988, Stability of the flow of a thin layer of liquid metal in a coplanar magnetic field, Magnetohydrodynamics, 24, 5-10.

3. Alpher, R.A., Hurwitz, H., Johnson, R.H., White, D.R., 1960, Some studies of freesurface mercury magnetohydrodynamics, Rev. Mod. Phys., 32, 758-769.

4. Alty, C.J.N., 1971, Magneto hydrodynamic duct flow in a uniform transverse magnetic field of arbitrary orientation, $J$. Fluid Mech., 48, 429-461.

5. Badger, B. et al., 1974, Wisconsin toroidal fusion reactor design study, Technical Report UWFDM-68, University of Wisconsin, Madison, 2.

6. Baranov, V.V., Evtushenko, I.A., Kirillov, I.R., Firsova, E.V., Yakovlev, V.V., 1994, Liquid metal film flow for fusion applications, Magnetohydrodynamics, 30, 460-467.

7. Bucenieks, I., Lielausis, O., Platacis, E., Shishko, A., 1994, Experimantal study of liquid metal film and jet flows in a strong magnetic field, Magnetohydrodynamics, 30 , 219-230.

8. Bühler, L. 1995, The influence of small cracks in insulating coatings on the flow structure and pressure drop in MHD channel flows, Fusion Engng Design, 27, 650658.

9. Bühler, L., Molokov, S. 1993, Magneto hydrodynamic flows in ducts with insulating coatings, Kernforschungszentrum Karlsruhe, KfK 5103.

10. Dem'yanenko, V.N., Karasev, B.G., Kolesnichenko, A.F., Lavrent'ev, I.V., Lielausis, O.A., Murav'ev, E.V., Tananaev, A.V., 1988, Liquid metal in the magnetic field of a tokamak reactor, Magnetohydrodynamics, 24, 104-124.

11. Dem'yanenko, V.N., Vodyanyuk, V.O., Kolesnichenko, A.F., 1990, Shaping of Liquid Metal Flows with Predetermined Parameters in Tokamak Magnetic Field, Report to US-USSR Topical Meeting Collaborative Studies of Liquid Metal Blanket and Diverter Including Development of a Liquid Metal Blanket Module for Joint 
Testing in ALEX, Argonne National Laboratory, unpublished information, Nov.-Dec. 1990.

12. Evtushenko, I.A., Smolentsev, S.Y., Tananaev, A.V., 1991, Hydrodynamics and exchange of heat in thin liquid-metal layers within a magnetic field, Magnetohydrodynamics, 27, 287-291.

13. Gailitis, A., 1966, Oscillations of a conducting drop in a magnetic field, Magnetohydrodynamics, 2, 47-53.

14. Gailitis, A., Gerbeth, G., 199I, The effect of a magnetic field on the thermo capillary motion in a conducting droplet, Magnetohydrodynamics, 27, 166-169.

15. Grinberg, G.K., Kaudze, M.Z., Lielausis, O.A., Muraviev, E.V., 1982, Trajectory of free-falling conducting particles in a nonuniform magnetic field, Magnetohydrodynamics, 18, 46-50.

16. Hays, P.R., Walker, J.S., 1984, Liquid-metal MHD open-channel flows, Trans. ASME. E: J. Appl. Mech., 106, 13-18.

17. Hsieh, D.Y., 1965, Stability of conducting fluid flowing down an inclined plane in a magnetic field, Phys. Fluids, 8, 1785-1791.

18. Ivanov, A. B., 1988, Steady-state slow-changing flow of a free surface electroconducting liquid in electromagnetic field, Thesis, Leningrad, (as quoted in [6]).

19. Kaudze, M.Z., Lielausis, O.A., 1984, An impact of a drop on a liquid metal sufrace in a magnetic field, Magnetohydrodynamics, 20, 37-43.

20. Kirillina, E.M., 1989, Liquid metal film stability in a strong uniform magnetic field of arbitrary orientation, Magnetohydrodynamics, 25, 125-127.

21. Kirillov, I. R., Yakolev, V. V., Baranov, V. V., 1992, Some experimental results on MHD film flow in support of benchmark problem, Presented at the USA/Russia Workshop, Argonne National Laboratory, unpublished information, July-August, 1992.

22. Kudrin, V.M., Smolentsev, S.Yu., Tananaev, A.V., 1993, Developed flow of a thin liquid metal layer in an inclined magnetic field, Magnetohydrodynamics, 29, 66-70.

23. Lavrentiev, I.V., Molokov, S., Sidorenkov, S.I., Shishko, A.Ya., 1990, Stokes flow in a rectangular magneto hydrodynamic channel with nonconducting walls within a 
nonuniform magnetic field at large Hartmann numbers, Magnetohydrodynamics, 26, 328-338.

24. Lebedev, M.E., Fokin, B.S., Yakovlev, V.V., 1990, MHD free-surface flow in a model of a contact diverter device, In: Liquid Metals in Thermonuclear Energetics, Trudi TsKTI, No.264, 80-91.

25. Lebedev, M.E., Fokin, B.S., Yakovlev, V.V., Firsova, E. V., 1989, MHD flow having a free surface on a diverter contact assembly model, Argonne National Laboratory ( unpublished information).

26. Liao, C., LaBombard, B., Kazimi, M.S., 1992, MHD effects on liquid metal film flow, In: "NURETH-5. Proc. Sth Topical Meeting on Reactor Thermal Hydraulics, Salt Lake City, USA, 21-24 Sept. 1992", 1089-1096.

27. Liquid film coating, Eds.: S.F.Kistler, P.M.Schweitzer, (Chapman\& Hall: London), 1997.

28. Mazul, I. V., Saksagansky, G. L. 1990 Diverter targets of fusion tokamak-reactors I. Operational conditions and basic concepts. Plasma Devices and Operätions, 1, 103114.

29. Mirnov, S.V., Dem'yanenko, V.N., Muraviev, E.V., 1992, Liquid metal tokamak diverters, J. Nuclear Mater., 196-198, 45-49.

30. Molokov, S., Bühler, L. \& Stieglitz, R. 1995 Asymptotic structure of magneto hydrodynamic flows in bends. Magnetohydrodynamics, 31, 357-365.

31. Molokov, S. 1997 Towards advanced liquid metal blankets: resolving MHD-related problems. Proc. Int. Workshop on Liquid Metal Blanket Experimental Activities. Paris, 16-18 Sept. 1997.

32. Molokov, S., Reed, C.B. 2000 Fully developed magneto hydrodynamic flow in a rivulet. ANL Report No. ANL/TD/TM00-12.

33. Molokov, S., 1990, Magneto hydrodynamic flow in a rectangular channel in a strong skewed magnetic field, In: Proc. 13th Riga Conference on Magnetohydrodynamics, Riga 1990, 1, 23-24. (In Russian)

34. Molokov, S., Shishko, A., 1993, Fully developed magneto hydrodynamic flows in rectangular ducts with insulating walls, Kernforschungszentrum Karlsruhe. KfK 5247.

35. Moreau, R., 1990, Magnetohydrodynamics, (Kluwer: Amsterdam). 
36. Morley, N.B., Abdou, M.A., 1995, Modelling of fully-developed, liquid metal, thin film flows for fusion diverter applications, Fusion Engng Design, 30, 339-356.

37. Morley, N.B., Abdou, M.A., 1997, Study of fully developed, liquid-metal, openchannel flow in a nearly coplanar magnetic field, Fusion Technology, 31, 135-153.

38. Morley, N.B., Gaizer, A.A., Abdou, M.A., 1995, Estimates of the effect of a plasma momentum flux on the free surface of a thin film of liquid metal, Fusion Engng. Design, 28, 176-180.

39. Morley, N.B., Gaizer, A.A., Tillack, M.S., Abdou, M.A., 1995, Initial liquid metal magneto hydrodynamic thin film flow experiments in the MeGA-loop facility at UCLA, Fusion Engng. Design, 28, 725-730.

40. Morley, N.B., Roberts, P.H., 1996, Solutions of uniform, open-channel, liquid metal flow in a strong, oblique magnetic field, Phys. Fluids, 8, 923-935.

41. Morley, N.B., Tillack, M.S., 1993, Examination of stability calculations for liquid metal film flows in a coplanar magnetic field, Magnetohydrodynamics (Russian edition), 29, 69-75.

42. Morley, N.B., Tillack, M.S., Abdou, M.A., 1991, Analysis of liquid metal thin film protection of fusion reactor limiter-diverter surfaces, Fusion Technol., 19, 1765-1771.

43. Muraviev, E.V., 1980, On the motion of conducting spherical particles in a nonuniform magnetic field, Magnetohydrodynamics, 16, 43-50.

44. Muraviev, E.V., 1988, Film MHD flow under conditions of a thermonuclear reactor, Magnetohydrodynamics, 24, 125-138.

45. Muraviev, E.V., 1995, Liquid-metal-colled diverter for ARIES, Fusion Engng Design, 29, 98-104.

46. Muraviev, E.V., 1997, MHD film flow model for tokamak reactor diverter plates, Magnetohydrodynamics, 33, 475-479.

47. Muraviev, E.V., 1995, Open surface MHD flow of liquid metal coolant in a rotating diverter target of a tokamak fusion reactor, Magnetohydrodynamics, 31, 306-314.

48. Muraviev, E.V., Petrov, V.S., Romanov, P.V., Topilski, L.N., Kashirski, A.V. et al., 1994, Liquid-metal-colled diverter for ARIES, Technical Report of General Atomics GA-A21755, General Atomics, San Diego, CA. 
49. Oshima, S., Yamane, R., 1991, Shape-control of liquid metal free surfaces by means of a static magnetic field, In: Magnetohydrodynamics in Process Metallurgy, Eds.: Szekely, J., Evans, J.W., Blazek, K., El-Kaddah, N., The Minerals, Metals\&Materials Society, 251-259.

50. Oshima, S., Yamane, R., Mochimaru, Y., Matsuoka, T., 1987, The shape of a liquid metal jet under a non-uniform magnetic field, JSME Int. J., 30, 437-448.

51. Oshima, S., Yamane, R., Mochimaru, Y., Sudo, K., 1986a, Investigation on film flow of a conducting fluid in a transverse magnetic field (1st report, film flow in a non-uniform magnetic field), Bull. JSME., 29 (253), 2070-2077.

52. Oshima, S., Yamane, R., Mochimaru, Y., Sudo, K., 1986b, Investigation on film flow of a conducting fluid in a transverse magnetic field (2nd report, rivulet in a nonuniform magnetic field), Bull. JSME., 29 (253), 2078-2085.

53. Shercliff, J.A., 1969, Anisotropic surface waves under a vertical magnetic force, $J$. Fluid Mech., 38, 353-364.

54. Shishko, A.Ya., 1992, Wave phenomena on the surface of a magnetohydrodynamically levitated fluid, Magnetohydrodynamics, 28, 56-64.

55. Shishko, A.Ya., 1992, A theoretical investigation of steady-state film flows in a coplanar magnetic field, Magnetohydrodynamics, 28, 170-182.

56. Tananaev, A.V., Chehonadskih, A.I., Yakovlev, V.V., 1981, Influence of a perpendicular magnetic field on liquid metal flow in a chute, In: Magnetohydrodynamics in Metallurgy and Foundry, Kiev, 2, 14-20 (In Russian).

57. Tananaev, A.V., Murav'er, E.V., Yakovlev, V.V., 1989, Investigation of Film MHD Flow as Applied to the Problem of Developing Liquid Metal Diaphragms and Collector Devices of a Diverter in a Thermonuclear Tokamak Reactor, All-union Conference on Engineering Problems of Thermonuclear Reactors, ANL-TRANS-89-3.

58. Vodyanyuk, V.O., Dem'yanenko, V.N., Kolesnichenko, A.F., Mirnov, S.V., Muraviev, E.V., Sergeev, E.K., Shapiro, A.M., May 1988, Liquid-metal tokamak limiter: statement of the problem and first results, Sov. J. Plasma Phys. 14, 370-373

59. Walker, J.S., 1975, Open channel MHD flows, Proc. Beer Sheva Seminar on MHD Flows and Turbulence, 41-48. 
60. Walker, J.S., 1975, Uniform open channel liquid metal flows with transverse magnetic fields, Developments in Mechanics, vol. 8: Proc. 14th Midwestern Mechanics Conference. (Plenum: New York), 421.

61. Karasev, B.G., Tananaev, A.V. 1990, Liquid metal fusion reactor systems, Plasma devices and operations, 1, 11-30. 


\section{Table 2.1 Thermophysical properties of typical liquid metals}

\begin{tabular}{ccrcccc}
\hline Liquid metal & $\begin{array}{c}\text { Temperature, } \\
{ }^{\circ} \mathrm{C}\end{array}$ & $\begin{array}{c}\text { Density, } \rho, \\
\mathbf{k g} / \mathrm{m}^{3}\end{array}$ & $\begin{array}{c}\text { Electrical } \\
\text { conductivity, } \sigma, \\
(\Omega \mathrm{m})^{-1}\end{array}$ & $\begin{array}{c}\text { Surface tension, } \gamma, \\
\mathrm{N} \mathrm{m}^{-1}\end{array}$ & $\begin{array}{c}\text { Kinematic viscosity, } \\
\nu . \mathrm{m}^{2} / \mathrm{s}\end{array}$ & Capillary length, $l_{c e}, \mathrm{~cm}$ \\
\hline $\mathrm{Li}$ & 300 & 500 & $3.343410^{6}$ & 0.395 & $9.0010^{-7}$ & 1.27 \\
$\mathrm{Na}^{22} \mathrm{~K}^{78}$ & 100 & 847 & $2.878010^{6}$ & 0.120 & $5.5310^{-7}$ & 0.53 \\
$\mathrm{Ga}$ & 30 & 6093 & $3.850010^{6}$ & 0.718 & $3.1010^{-7}$ & 0.49 \\
$\mathrm{Ga}^{68}{ }^{20}{ }^{20} \mathrm{Sn}^{12}$ & 20 & 6363 & $3.307410^{6}$ & 0.353 & $4.0010^{-7}$ & 0.37 \\
$\mathrm{Hg}$ & 20 & 13546 & $1.044510^{6}$ & 0.480 & $1.1510^{-7}$ & 0.27 \\
\hline
\end{tabular}


Table 2.2 Dimensionless parameters for typical liquid metals,

and for $\dot{B_{0 .}}=10 \mathrm{~T}, a_{.}=5 \mathrm{~mm}, v_{0}=1 \mathrm{~m} / \mathrm{s}(F r=20)$.

\begin{tabular}{cccccccc}
\hline Liquid metal & Temperature, ${ }^{\circ} \mathrm{C}$ & $\mathrm{Ha}$ & $\mathrm{Re}$ & $N$ & $\mathrm{Bo}$ & $\mathrm{Ca}$ & $W e$ \\
\hline $\mathrm{Li}$ & 300 & 4307 & 5556 & 3339 & 0.31 & $1.1510^{-3}$ & 6 \\
$\mathrm{Na}^{22} \mathrm{~K}^{78}$ & 100 & 3919 & 9041 & 1699 & 1.73 & $3.9010^{-3}$ & 35 \\
$\mathrm{Ga}$ & 30 & 2257 & 16129 & 316 & 2.08 & $2.6310^{-3}$ & 42 \\
$\mathrm{Ga}^{68} \mathrm{In}^{20} \mathrm{Sn}^{12}$ & 20 & 1802 & 12500 & 260 & 4.42 & $7.2110^{-3}$ & 90 \\
$\mathrm{Hg}$ & 20 & 1295 & 43478 & 39 & 6.92 & $3.2510^{-3}$ & 141 \\
\hline
\end{tabular}




\section{Table 3.1 MHD issues for liquid metal film flow}

\begin{tabular}{|c|c|c|c|c|c|}
\hline & ISSUE & IMPORTANCE ${ }^{\dagger}$ & $\begin{array}{l}\text { REFERENCES, } \\
\text { theoretical }\end{array}$ & $\begin{array}{l}\text { REFERENCES, } \\
\text { experimental }\end{array}$ & UNDERSTANDING $\$$ \\
\hline 1 & fully developed flow & 2 & $\begin{array}{c}1,20,30,31,56 \\
59,60\end{array}$ & 8,33 & A \\
\hline 2 & inclination of the field & 1 & $20,30,31,34$ & 22 & $\begin{array}{c}\text { A for fully developed } \\
\text { flows, } \\
\text { B for 3D flows }\end{array}$ \\
\hline 3 & $\begin{array}{l}\text { uniformity of film height due to 3-D } \\
\text { effects; the development length }\end{array}$ & 1 & - & $5,8,22$ & C \\
\hline 4 & film stability & 1 & $2,17,23,35$ & 5 & C \\
\hline 5 & $\begin{array}{l}\text { other inertial effects associated with } \\
\text { high-velocity jets in the parallel } \\
\text { layers }\end{array}$ & 3 & - & - & C \\
\hline 6 & possible hydraulic jumps & 1 & $56,30,31$ & $5,8,22$ & C \\
\hline
\end{tabular}




\section{Table 3.1 MHD issues for liquid metal film flow (Cont.)}

\begin{tabular}{|c|c|c|c|c|c|}
\hline 7 & $\begin{array}{l}\text { pressure drop in the supplying/draining } \\
\text { systems }\end{array}$ & 2 & $\begin{array}{l}\text { see references on } \\
\text { duct flow problems }\end{array}$ & see references on duct flow problems & $\begin{array}{l}\text { essentially a duct flow problem; } \\
\text { depends on a particular design }\end{array}$ \\
\hline 8 & $\begin{array}{l}\text { the effect of time-dependent magnetic } \\
\text { fields during plasma disruption }\end{array}$ & 1 & - & - & $\mathrm{C}$ \\
\hline 9 & heat-transfer analysis & 2 & - & - & B \\
\hline 10 & thermocapillary convection & 2 & - & - & $\mathbf{C}$ \\
\hline 11 & buoyant convection & 4 & - & - & B \\
\hline 12 & possible dry-out due to poor wettability & 1 & - & 22,48 & $\mathbf{B}$ \\
\hline 13 & plasma wind & 1 & 23,32 & - & C \\
\hline 14 & $\begin{array}{l}\text { dependence of the electrical } \\
\text { conductivity on temperature }\end{array}$ & 3 & - & - & C \\
\hline 15 & $\begin{array}{l}\text { the effect of imperfect insulation of } \\
\text { coatings }\end{array}$ & 3 & - & - & B \\
\hline 16 & $\begin{array}{l}\text { the effect of the magnetic field on static } \\
\text { and dynamic contact angles }\end{array}$ & 3 & - & - & C \\
\hline
\end{tabular}

${ }^{\dagger}$ Key: 1 -crucial, 2-important, 3-potentially important, 4-not important at this stage

Key: A-good, B-insufficient, $\mathrm{C}$ - poor 


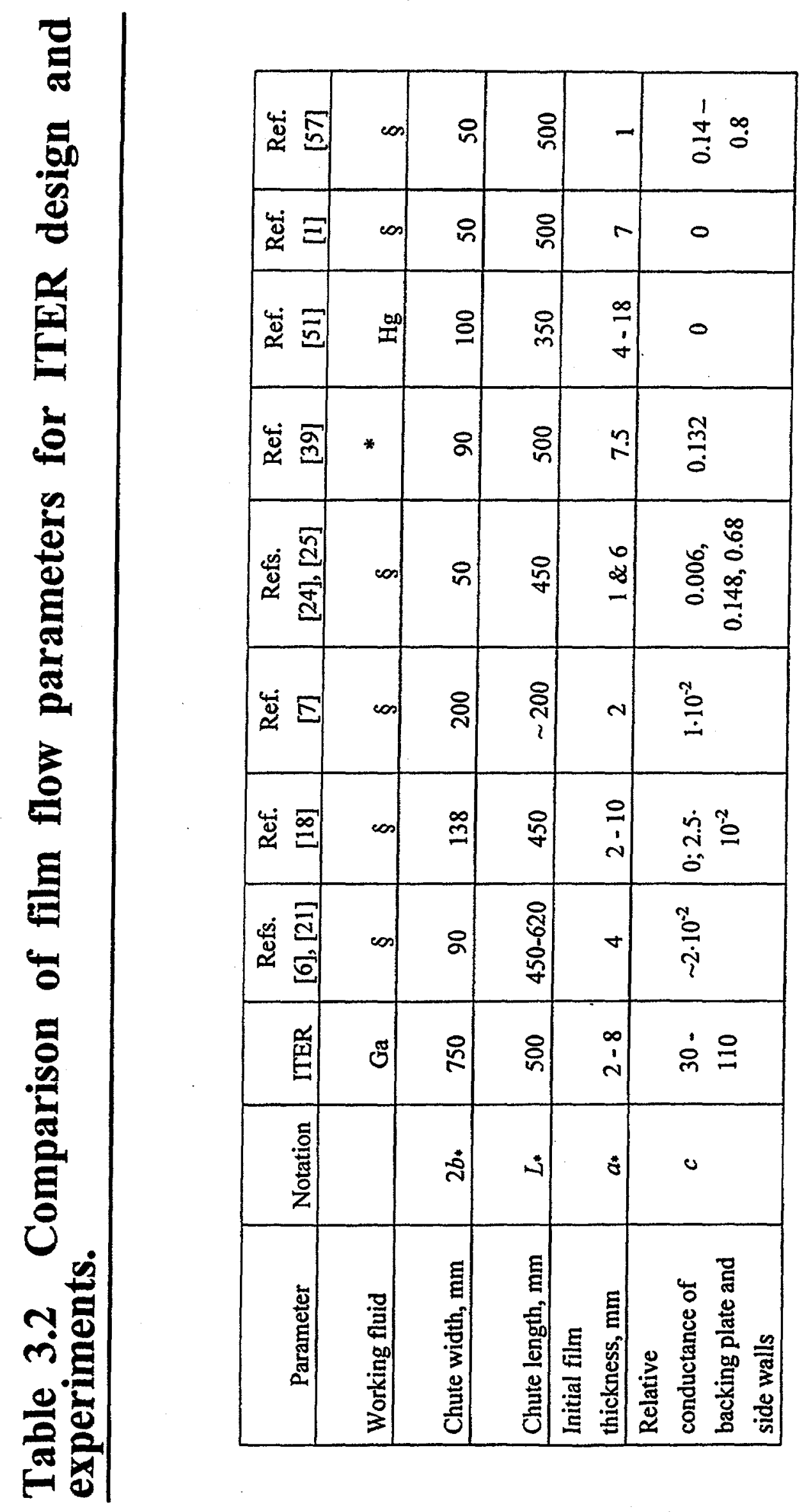




\section{Table 3.2 Comparison of film flow parameters for ITER design and experiments. (Cont.)}

\begin{tabular}{|c|c|c|c|c|c|c|c|c|c|c|}
\hline Parameter & Notation & ITER & $\begin{array}{l}\text { Refs. } \\
{[6],[21]}\end{array}$ & $\begin{array}{l}\text { Ref. } \\
{[18]}\end{array}$ & $\begin{array}{l}\text { Ref. } \\
{[7]}\end{array}$ & $\begin{array}{c}\text { Refs. } \\
{[24],[25]}\end{array}$ & $\begin{array}{l}\text { Ref. } \\
{[39]}\end{array}$ & $\begin{array}{l}\text { Ref. } \\
{[51]}\end{array}$ & $\begin{array}{l}\text { Ref. } \\
{[1]}\end{array}$ & $\begin{array}{l}\text { Ref. } \\
{[57]}\end{array}$ \\
\hline $\begin{array}{l}\text { Backing plate } \\
\text { inclination angle to } \\
\text { horizon, deg. }\end{array}$ & $\alpha$ & $\sim 3$ & $30 / 40 / 60$ & $0-5$ & $10-30$ & 0 & 1 & $0 ; 1$ & 0 & 0 \\
\hline $\begin{array}{l}\text { Max. magnetic } \\
\text { field induction, } \mathrm{T}\end{array}$ & $B_{0^{*}}$ & $\sim 7$ & 0.8 & 1.0 & 4 & 0.5 & $\sim 0.18$ & 1.4 & 1.25 & 1.5 \\
\hline $\begin{array}{l}\text { B-field direction } \\
\text { angle to backing } \\
\text { plate, degrees }\end{array}$ & $\beta$ & $\sim 3$ & $0 \& 7$ & 0 & 0 & $0 ; 12$ & 0 & 0 & 0 & 0 \\
\hline Mean velocity, $\mathrm{m} / \mathrm{s}$ & $v_{0^{*}}$ & $1-10$ & $\begin{array}{c}0.18- \\
1.25 \\
\end{array}$ & $\begin{array}{c}0.02- \\
1.36 \\
\end{array}$ & $0.2-0.5$ & $0.5-4.2$ & $\begin{array}{c}0.5 \& \\
0.08\end{array}$ & $\begin{array}{c}0.07- \\
0.2\end{array}$ & -1 & $1-4.2$ \\
\hline $\begin{array}{l}\text { Normalized initial } \\
\text { film thickness }\end{array}$ & $h / b$ & $\begin{array}{c}0.003- \\
0.011 \\
\end{array}$ & 0.089 & $\begin{array}{l}0.03- \\
0.145\end{array}$ & 0.02 & $0.04-0.24$ & 0.167 & 0.24 & 0.28 & 0.04 \\
\hline $\begin{array}{l}\text { Number of MHD } \\
\text { data points }\end{array}$ & & & -218 & & qualitative & $\sim 190$ & $\sim 18$ & $\begin{aligned} & \sim 32 \\
&+ \text { curves } \\
&\end{aligned}$ & $\sim 20$ & 68 \\
\hline
\end{tabular}

$\S$ In-Ga-Sn

* $44.7 \% \mathrm{Bi}, 22.6 \% \mathrm{~Pb}, 19.1 \% \mathrm{In}, 8.3 \% \mathrm{Sn}, 5.3 \% \mathrm{Cd}$ 


\section{Table 3.3 Comparison of dimensionless film flow parameters for ITER}

design and experiments.

\begin{tabular}{|l|c|c|c|c|c|c|c|c|c|c|}
\hline Parameter & Notation & ITER & Polzunov & $\begin{array}{c}\text { St. P } \\
\text { Poly }\end{array}$ & Riga & $\begin{array}{c}\text { St. P } \\
\text { Poly }\end{array}$ & UCLA & T I Tech & $\begin{array}{c}\text { St. P } \\
\text { Poly }\end{array}$ & $\begin{array}{c}\text { St. P. } \\
\text { Poly }\end{array}$ \\
\hline Max. Hartmann number & $\mathbf{H a}$ & $10^{4}-10^{5}$ & $\sim 130$ & $\sim 96$ & $\sim 310$ & $\sim 120$ & $\sim 34$ & $\sim 300$ & $\sim 350$ & $\sim 60$ \\
\hline $\begin{array}{l}\text { Max. MHD Interaction } \\
\text { parameter }\end{array}$ & $\boldsymbol{N}$ & $\sim 10^{3}$ & $\sim 7$ & $\sim 3$ & $\sim 82$ & $\sim 1.4$ & $\sim 0.4$ & $\sim 26$ & $\sim 5$ & $\sim 1$ \\
\hline $\begin{array}{l}\text { Max. MHD Gravitational } \\
\text { parameter }\end{array}$ & $\boldsymbol{F r} \cdot \boldsymbol{N}$ & $\sim 2 \bullet 10^{4}$ & $\sim 250$ & $\sim 110$ & $\sim 10^{3}$ & $\sim 5-50$ & $\sim 1$ & $\sim 4$ & $\sim 80$ & $\sim 15$ \\
\hline $\begin{array}{l}\text { Max. MHD Surface Tension } \\
\text { parameter }\end{array}$ & $\mathbf{H a}^{2} \cdot \mathbf{C a}$ & $\begin{array}{c}\sim 3 \bullet 10^{5} \\
-3 \bullet 10^{7}\end{array}$ & $\sim 120$ & $\sim 60$ & $\sim 700$ & $\sim 3-$ & $\sim 6$ & $\sim 50-600$ & $\sim 870$ & $\sim 25$ \\
\hline
\end{tabular}




\section{Table 4.1 MHD issues for liquid metal jets}

\begin{tabular}{|c|c|c|c|c|c|}
\hline & ISSUE & IMPORTANCE $^{\dagger}$ & $\begin{array}{l}\text { REFERENCES, } \\
\text { theoretical }\end{array}$ & $\begin{array}{l}\text { REFERENCES, } \\
\text { experimental }\end{array}$ & UNDERSTANDING ${ }^{\S}$ \\
\hline 1 & $\begin{array}{l}\text { 3-D entrance effects at the nozzle and } \\
\text { the development length }\end{array}$ & 2 & - & - & C \\
\hline 2 & spatially varying field & 2 & 46 & 46 & $\begin{array}{l}\text { B; further theoretical study } \\
\text { required }\end{array}$ \\
\hline 3 & jet stability in a strong transverse field & 1 & - & 8,46 & $\mathrm{C}$; no adequate theoretical results \\
\hline 4 & $\begin{array}{l}\text { impact of a jet on the solid wall or a } \\
\text { liquid surface }\end{array}$ & 2 & - & 8 & C; no theoretical results \\
\hline 5 & thermocapillary convection & 3 & - & - & $\begin{array}{c}\mathrm{C} \text {; theoretical analysis in } \\
\text { progress }\end{array}$ \\
\hline 6 & $\begin{array}{l}\text { the effect of time-dependent magnetic } \\
\text { fields during plasma disruption }\end{array}$ & 1 & - & - & C \\
\hline
\end{tabular}




\section{Table 4.1 MHD issues for liquid metal jets (Cont.)}

7 heat-transfer analysis

8 pressure drop in the supplying/draining systems

9 buoyant convection

10 plasma wind

11 dependence of the electrical conductivity on temperature

12 the effect of the magnetic field on static and dynamic contact angles

2

2

4

1

3

3

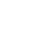

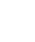
See references on duct flows
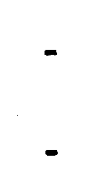

$-$
See references on duct flows depends on the particular design essentially duct flow problem;

not expected to be important

C

C

C

'Key: 1 - crucial, 2-important, 3-potentially important, 4-not important at this stage
Key: A-good, B-insufficient, C-poor 


\section{Table 5.1 MHD issues for liquid metal drops}

\begin{tabular}{|c|c|c|c|c|c|}
\hline & ISSUE & IMPORTANCE $^{\dagger}$ & $\begin{array}{l}\text { REFERENCES, } \\
\text { theoretical }\end{array}$ & $\begin{array}{l}\text { REFERENCES, } \\
\text { experimental }\end{array}$ & UNDERSTANDING ${ }^{\S}$ \\
\hline 1 & jet/film atomizer & 1 & - & 26 & c \\
\hline 2 & spatially varying field & 3 & 37 & 13 & B; further theoretical study required \\
\hline 3 & $\begin{array}{l}\text { drop stability/oscillations in a } \\
\text { strong transverse field }\end{array}$ & 3 & 11 & & B; further theoretical study required \\
\hline 4 & $\begin{array}{l}\text { impact of a drop on the solid } \\
\text { wall/shallow LM layer }\end{array}$ & 2 & - & 16 & C \\
\hline 5 & thermocapillary convection & 3 & 12 & - & B \\
\hline 6 & $\begin{array}{l}\text { the effect of time-dependent } \\
\text { magnetic fields during plasma } \\
\text { disruption }\end{array}$ & 4 & - & - & $\mathrm{C}$ \\
\hline 7 & heat-transfer analysis & 1 & - & - & B \\
\hline
\end{tabular}




\section{Table 5.1 MHD issues for liquid metal drops (Cont.)}

8 pressure drop in the

supplying/draining systems

10 plasma wind

11 dependence of the electrical conductivity on temperature
2

References on duct

References on duct flows

1

3 flows

$-$

$-$ essentially duct flow problem; depends on the concrete design

${ }^{\dagger}$ Key: 1 - crucial, 2-important, 3-potentially important, 4-not important at this stage

Key: A-good, B - insufficient, C-poor 
Table 5.2. Parameters of the "external" and "internal" effect of a nonuniform magnetic field on a spherical particle (from [37])

\begin{tabular}{|c|c|c|c|c|c|c|}
\hline & & & \multicolumn{2}{c|}{ Velocity, m/s } & \multicolumn{2}{c|}{} \\
\hline $2 \mathrm{a}, \mathrm{mm}$ & \multicolumn{2}{|c|}{3} & \multicolumn{2}{c|}{10} & \multicolumn{2}{c|}{30} \\
\hline \hline & $\mathrm{M}_{\mathrm{e}}$ & $\mathrm{M}_{\mathrm{i}}$ & $\mathrm{M}_{\mathrm{e}}$ & $\mathrm{M}_{\mathrm{i}}$ & $\mathrm{M}_{\mathrm{e}}$ & $\mathrm{M}_{\mathrm{i}}$ \\
\hline 0.3 & $3.810^{-4}$ & $4.310^{-4}$ & $1.210^{-4}$ & $1.410^{-3}$ & $3.810^{-5}$ & $4.310^{-3}$ \\
\hline 1 & $4.310^{-3}$ & $1.610^{-2}$ & $1.310^{-3}$ & $5.310^{-2}$ & $4.310^{-4}$ & $1.610^{-1}$ \\
\hline 3 & $3.810^{-2}$ & $4.310^{-1}$ & $1.210^{-2}$ & 1.4 & $3.810^{-3}$ & 4.3 \\
\hline
\end{tabular}




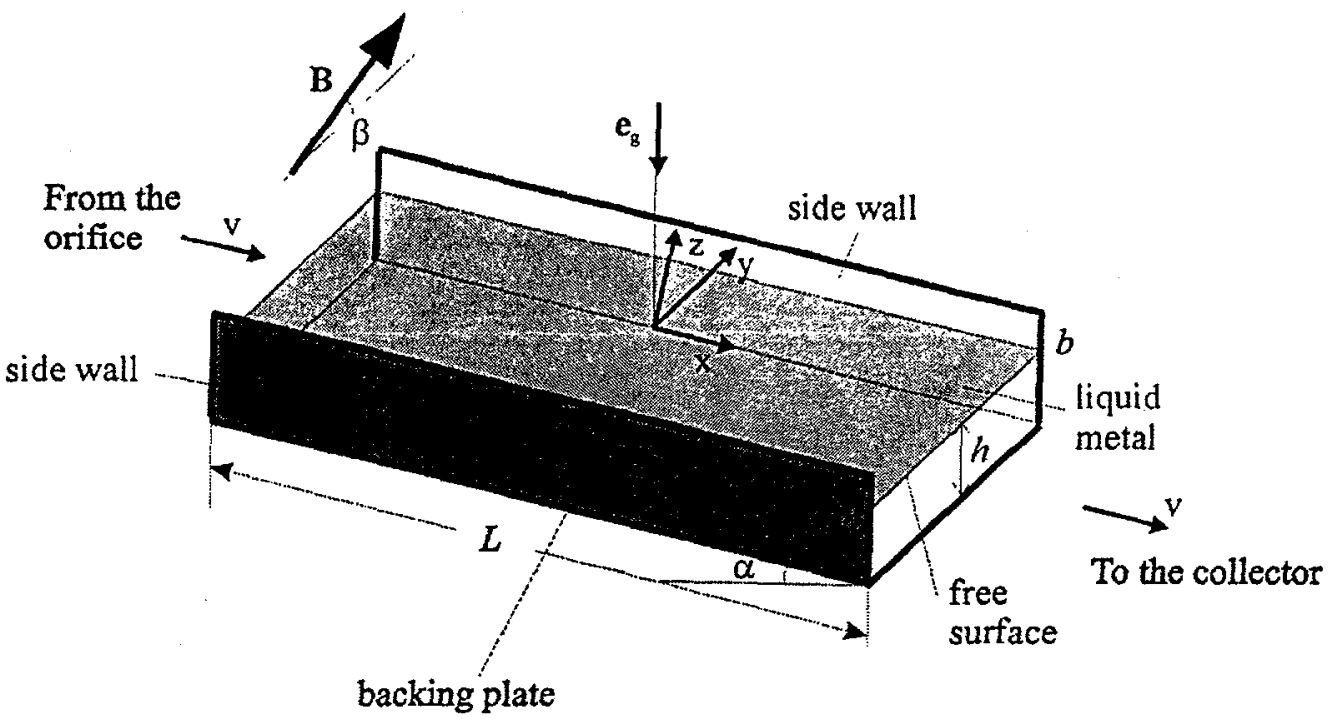

Figure 3.1. Liquid metal film flow down an inclined plate in a magnetic field applied in the $(y, z)$ - plane.

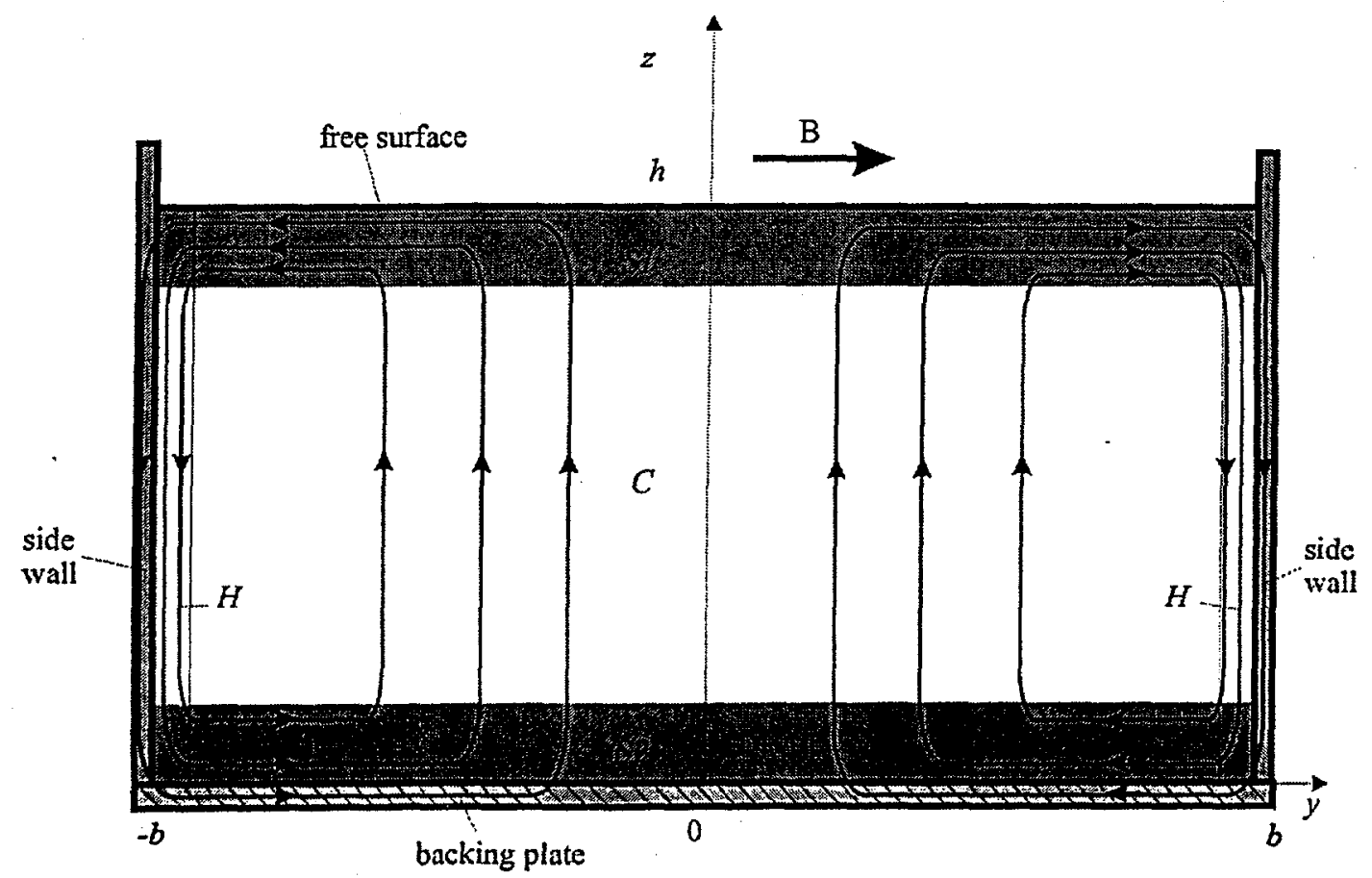

Figure 3.2 Liquid metal film flow: flow subregions at high Hartmann number for a coplanar field. 

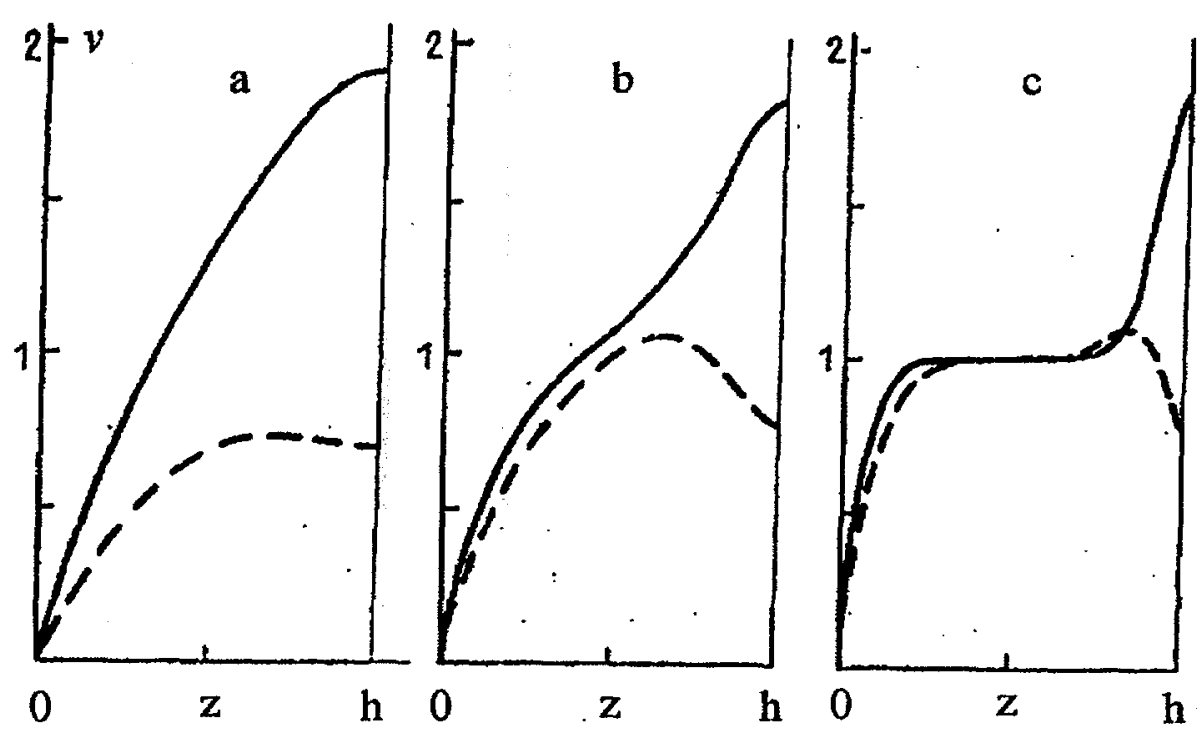

Figure 3.3 Velocity distribution over film thickness for insulating sidewalls and insulating backing plate for $y=0$ (center of the chute, solid line) and $y=0.99 b$ (at the sidewall, broken line). Here $\mathrm{Ha}_{\mathrm{b}}=10,000, \mathrm{~h} / \mathrm{b}=0.0104$ (a); $\mathrm{Ha}_{\mathrm{b}}=20,000$, $h / b=0.0164$ (b); $H a_{b}=40,000, h / b=0.0321$ (c). (from [55]).

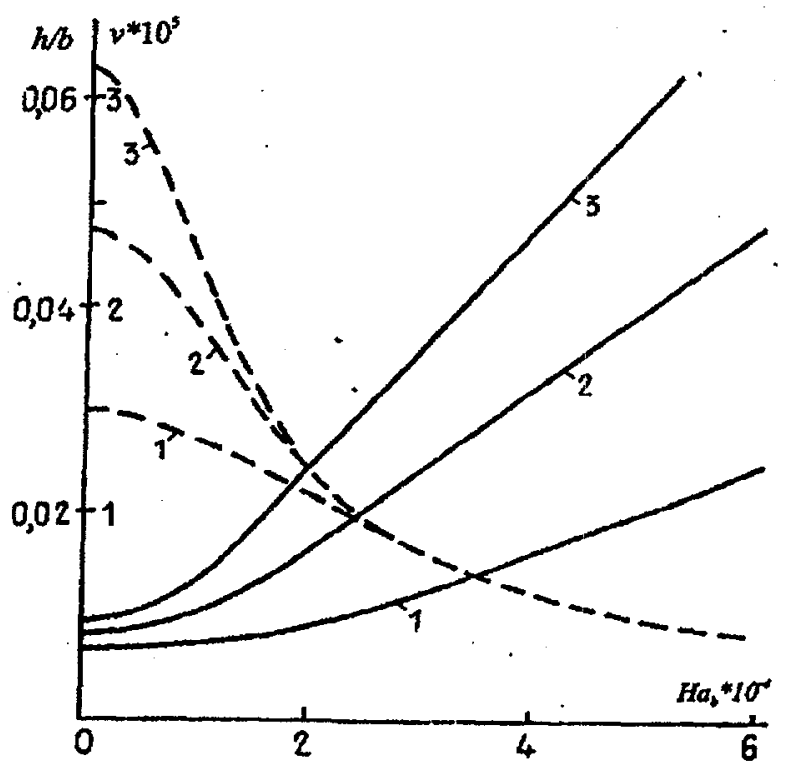

Figure 3.4 Variation of the normalized film thickness (solid line) and of the average velocity (broken lines) with $\mathrm{Ha}_{\mathrm{b}}$ for three different values of the flow rate. (from [55]). 

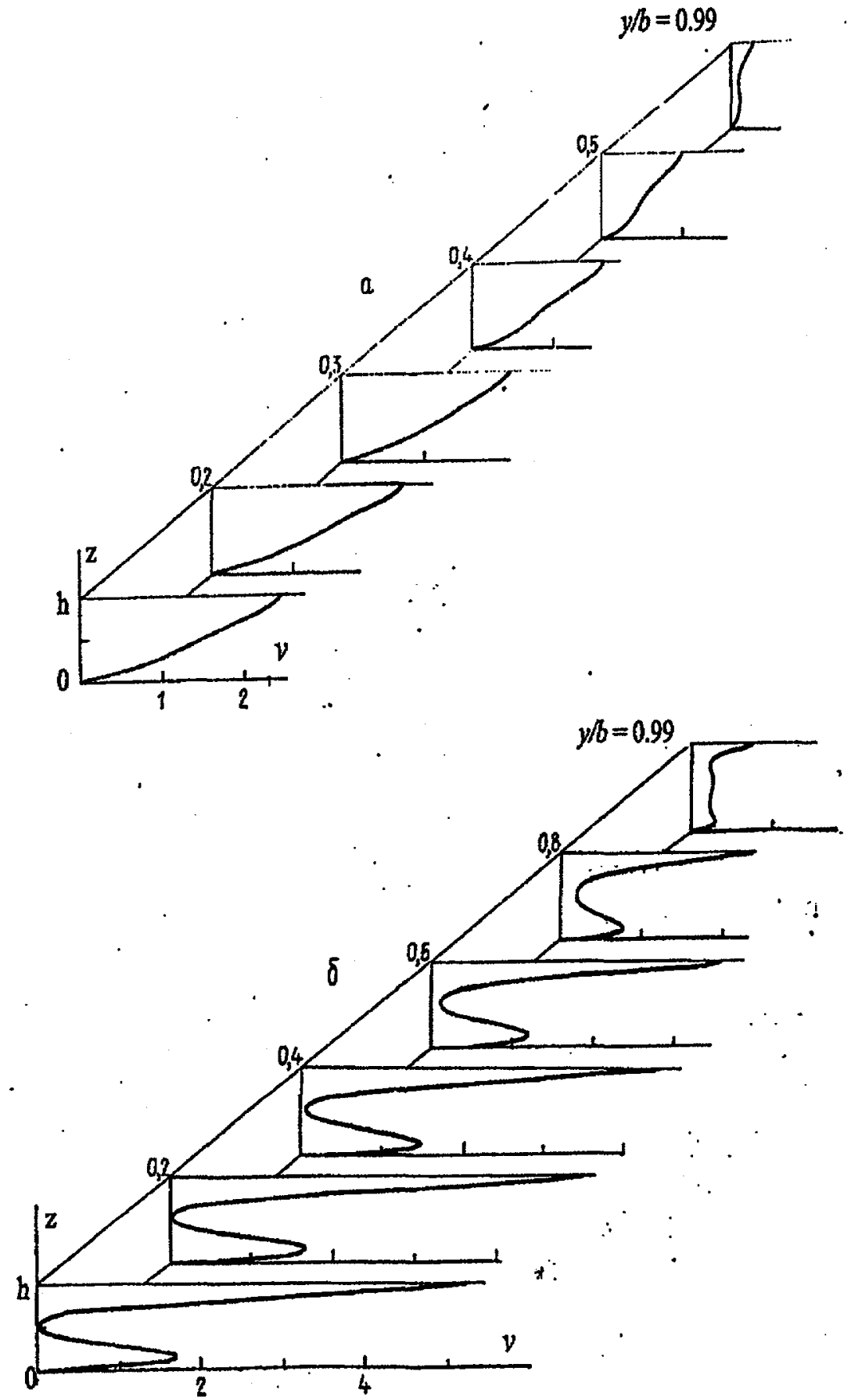

Figure 3.5 Velocity profiles in a chute with insulating backing plate and conducting sidewalls $(c=0,002)$ for $\mathrm{Ha}_{3}=12,750$ and for fast regime, $\mathrm{h} b=0.012$ (a), and slow regime, $W b=0.0325$ (b) (from [55]). 


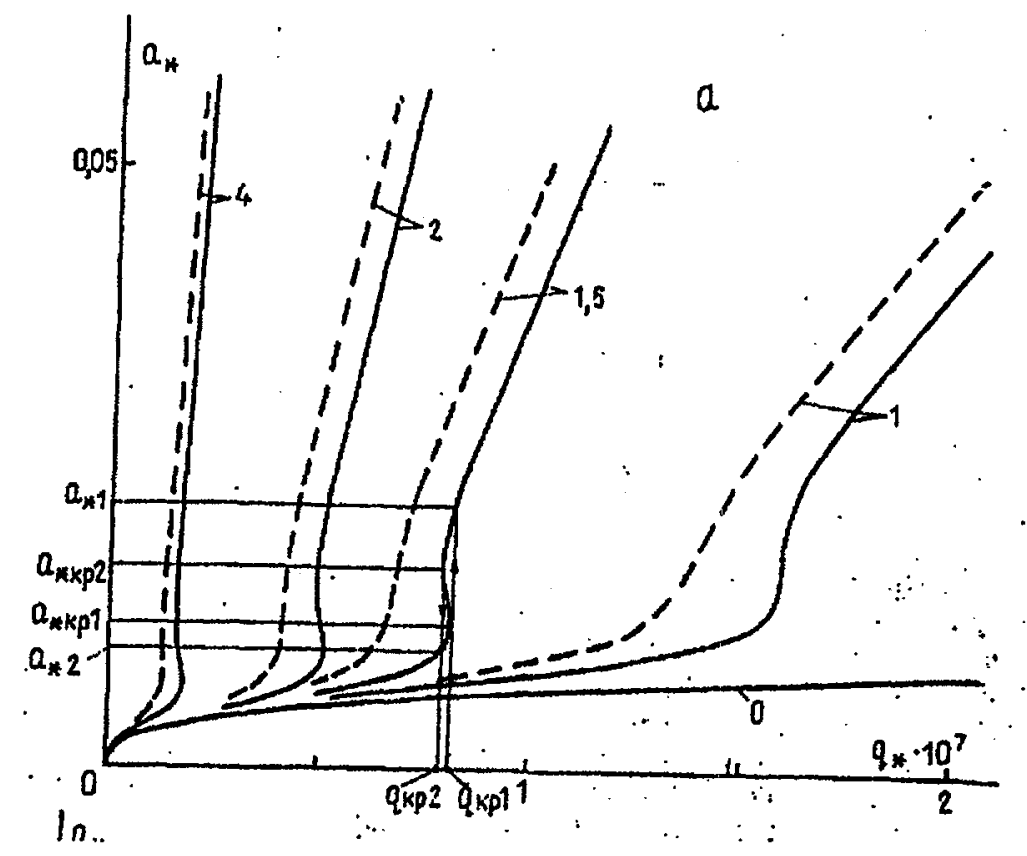

Figure 3.6 the thickness of the film is plotted against the flow rate for insulating (solid line) and conducting (broken line) backing plate for several values of $\mathrm{Ha}_{\mathrm{b}}{ }^{*} 1 \mathrm{O}^{-4}$ (from [55]).

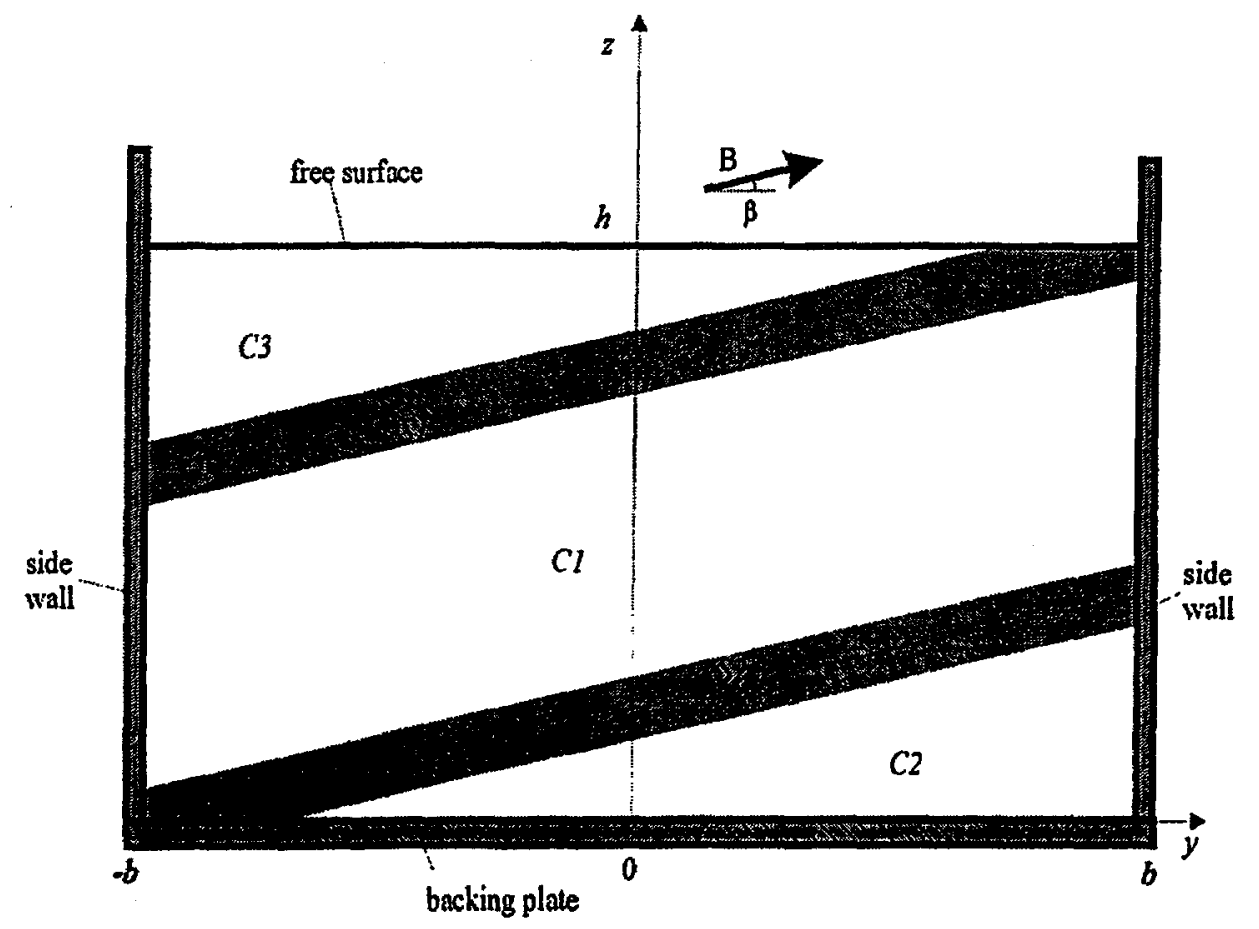

Figure 3.7 Flow subregions at high Hartmann number for Case I. 


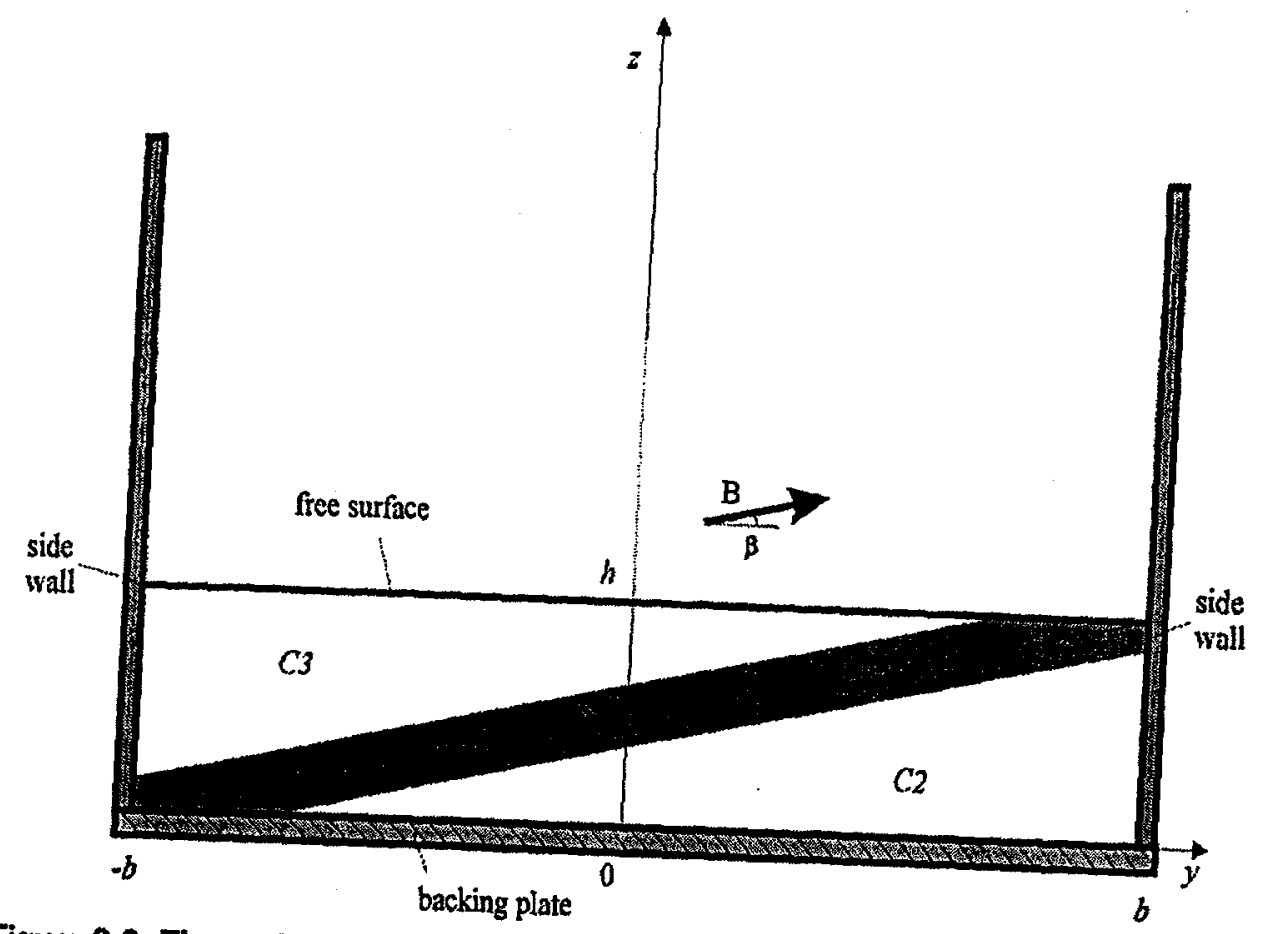

Figure 3.8 Flow subregions at high Hartmann number for Case II.

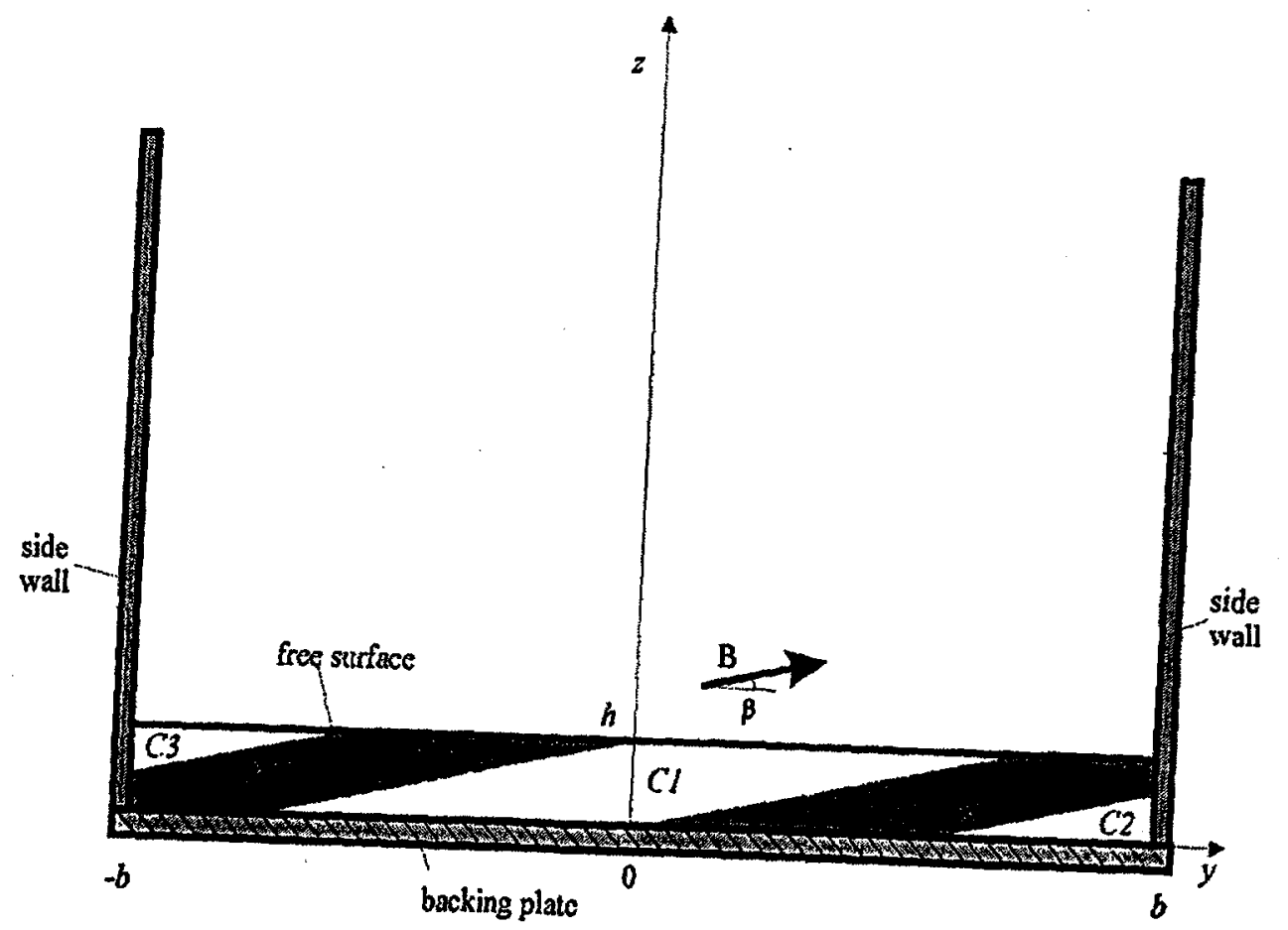

Figure 3.9 Flow subregions at high Hartmann number for Case III. 

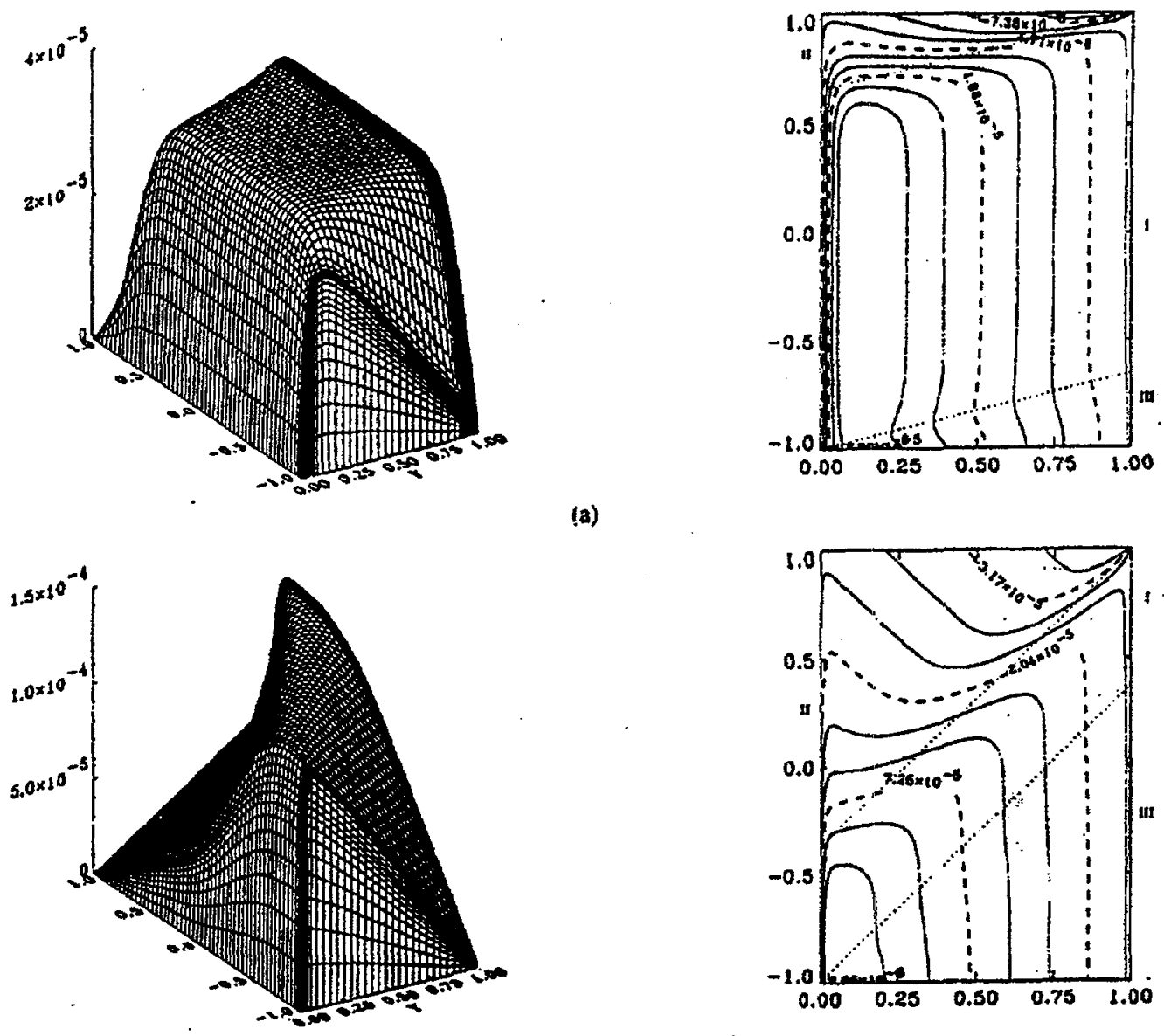

(b)
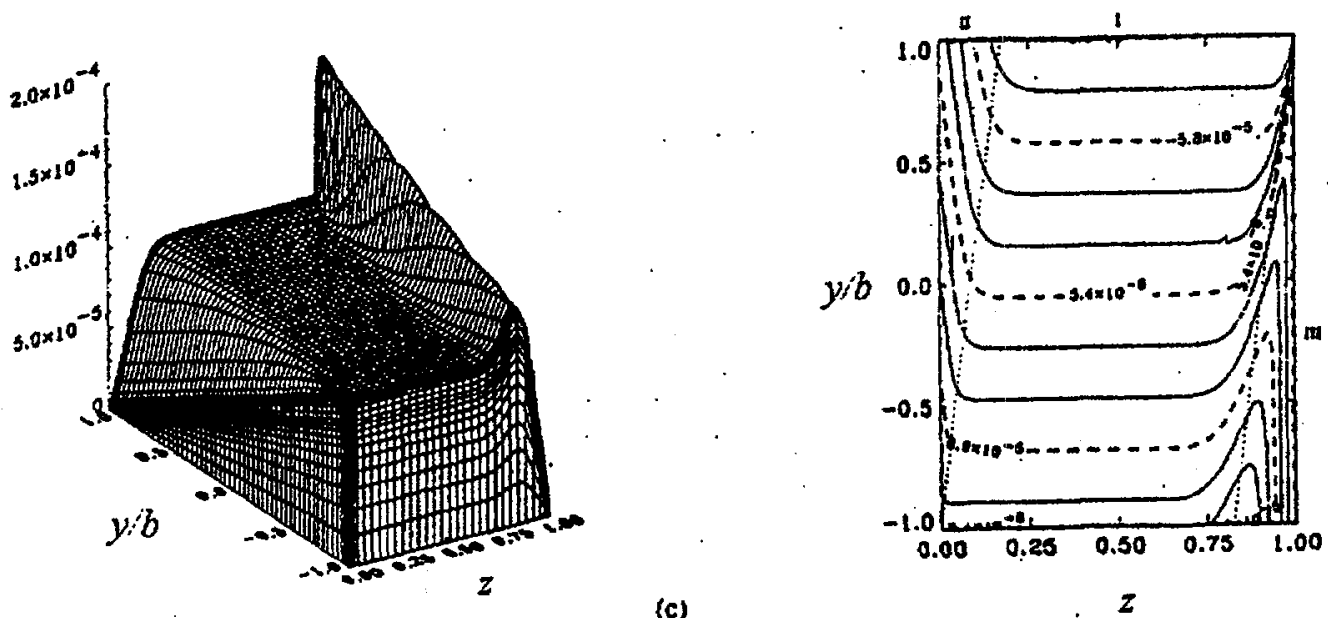

(c)

Figure 3.10. Velocity profiles and electric current lines for insulating sidewalls and backing plate. Here $b=5^{\circ}, \mathrm{Ha}_{b}=10,000, h / b=0.03(a), 0.12$ (b), 1 (c). (from [37]). 

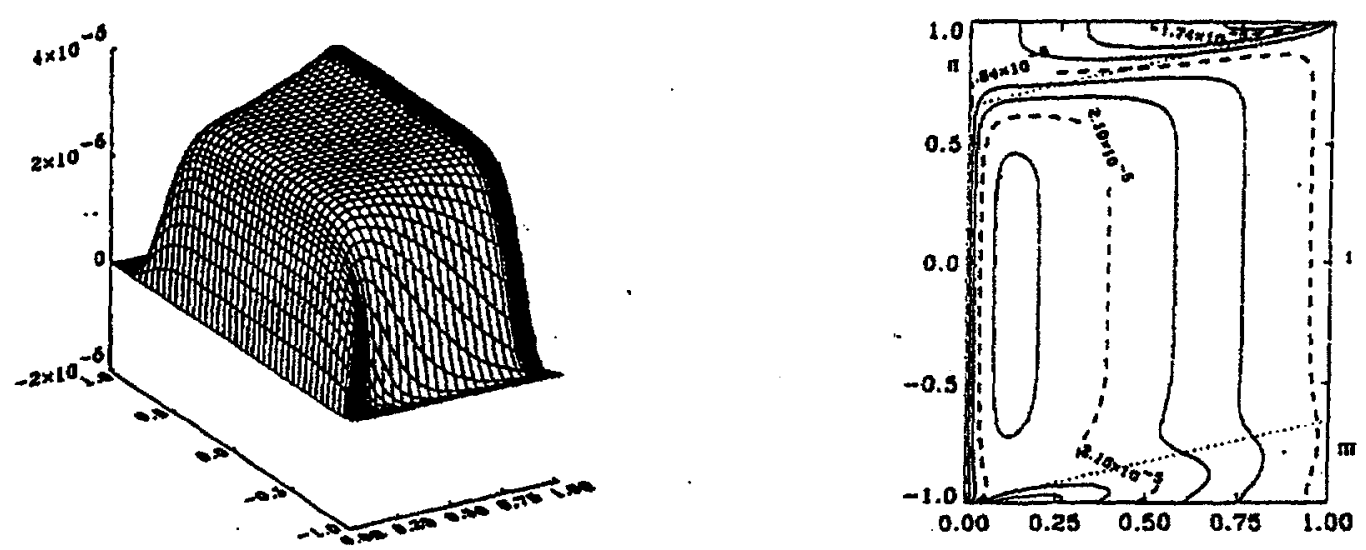

(a)
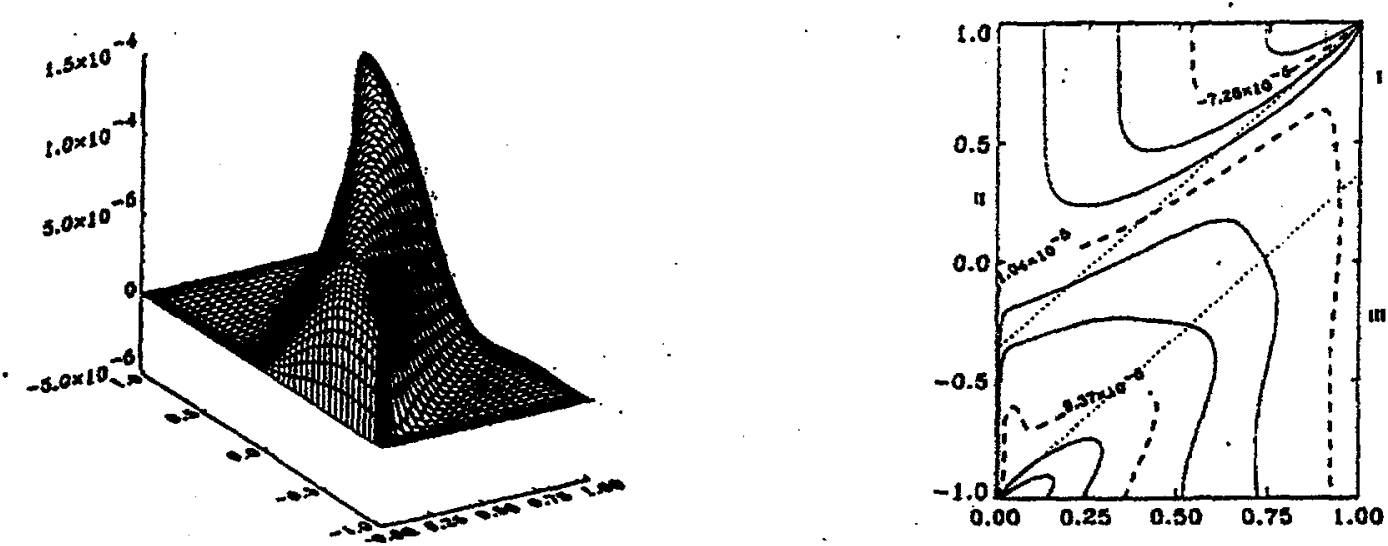

(b)
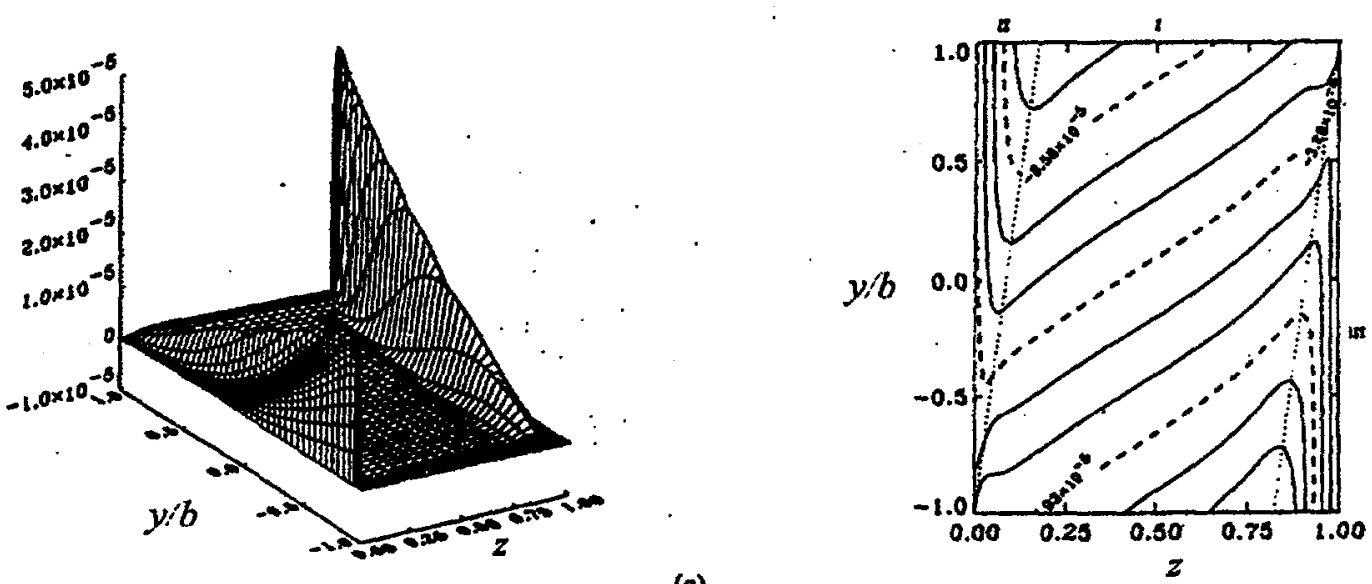

(c)

Figure 3.11. Velocity profiles and electric current lines for conducting sidewalls $\left(c=0.01\right.$ ) and insulating backing plate. Here $\mathrm{b}=5^{\circ}, \mathrm{Ha}_{\mathrm{b}}=10,000, \mathrm{~h} / \mathrm{b}=0.03(\mathrm{a}), 0.12$ (b), 1 (c). (from [37]). 


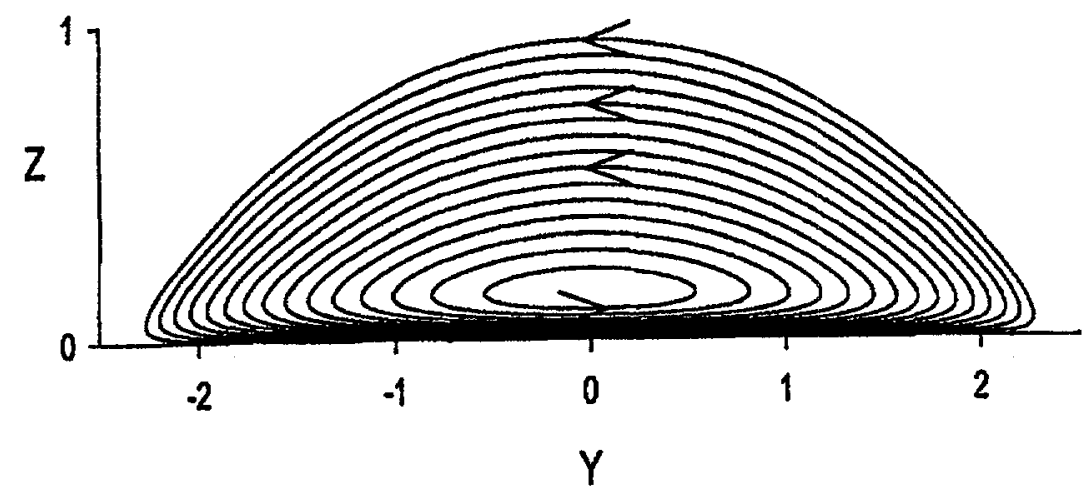

(a)

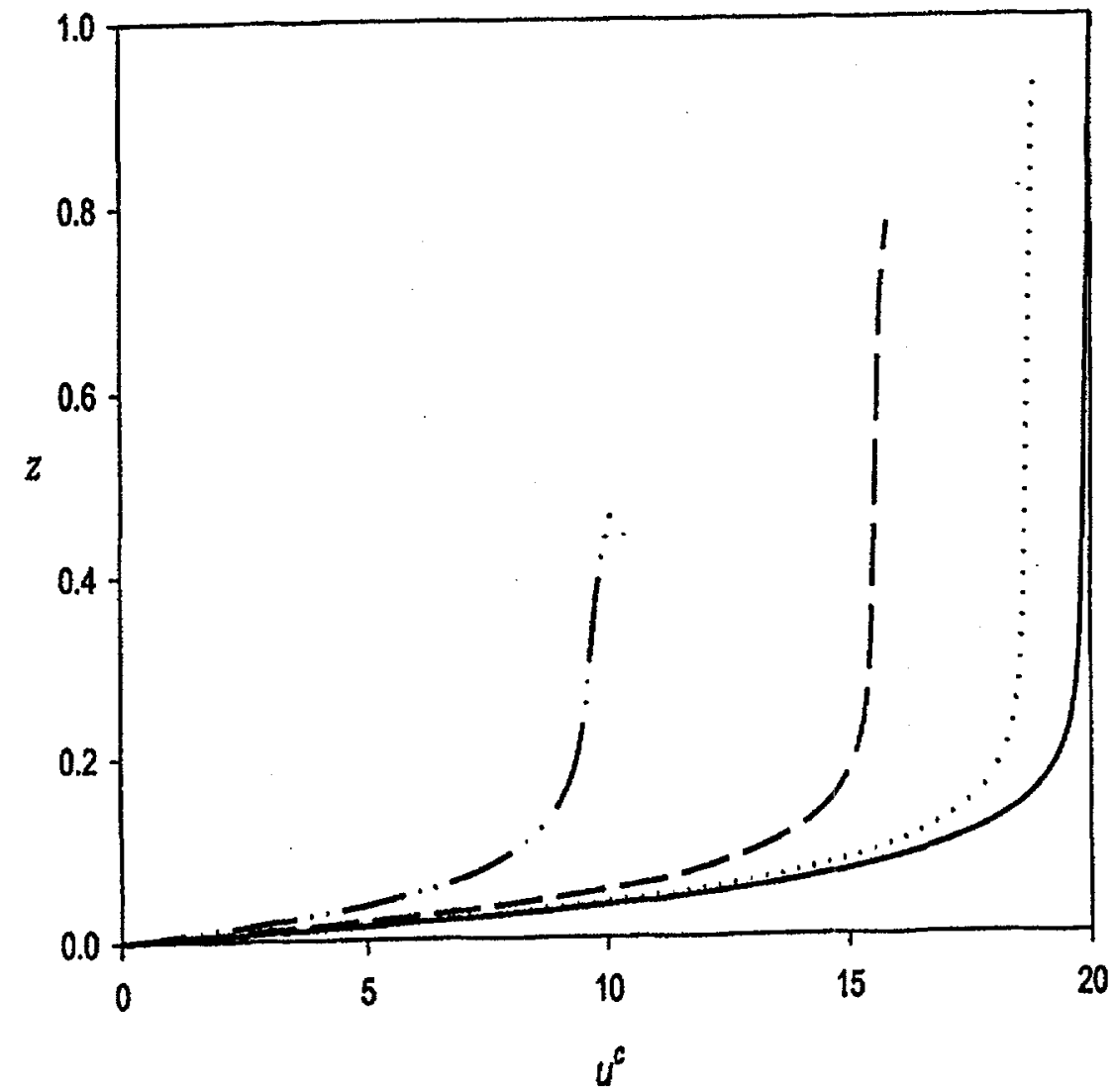

Figure 3.12. Rivulet in a transverse field: electric current lines (a) and velocity profiles (b) for $\mathrm{Ha}=20$ 


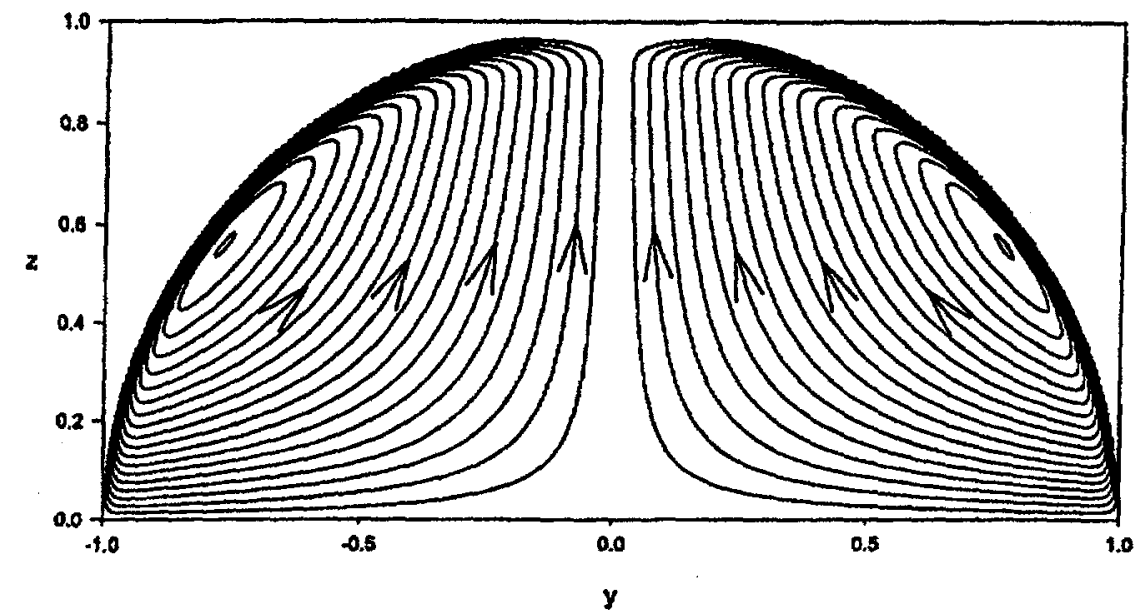

(a)

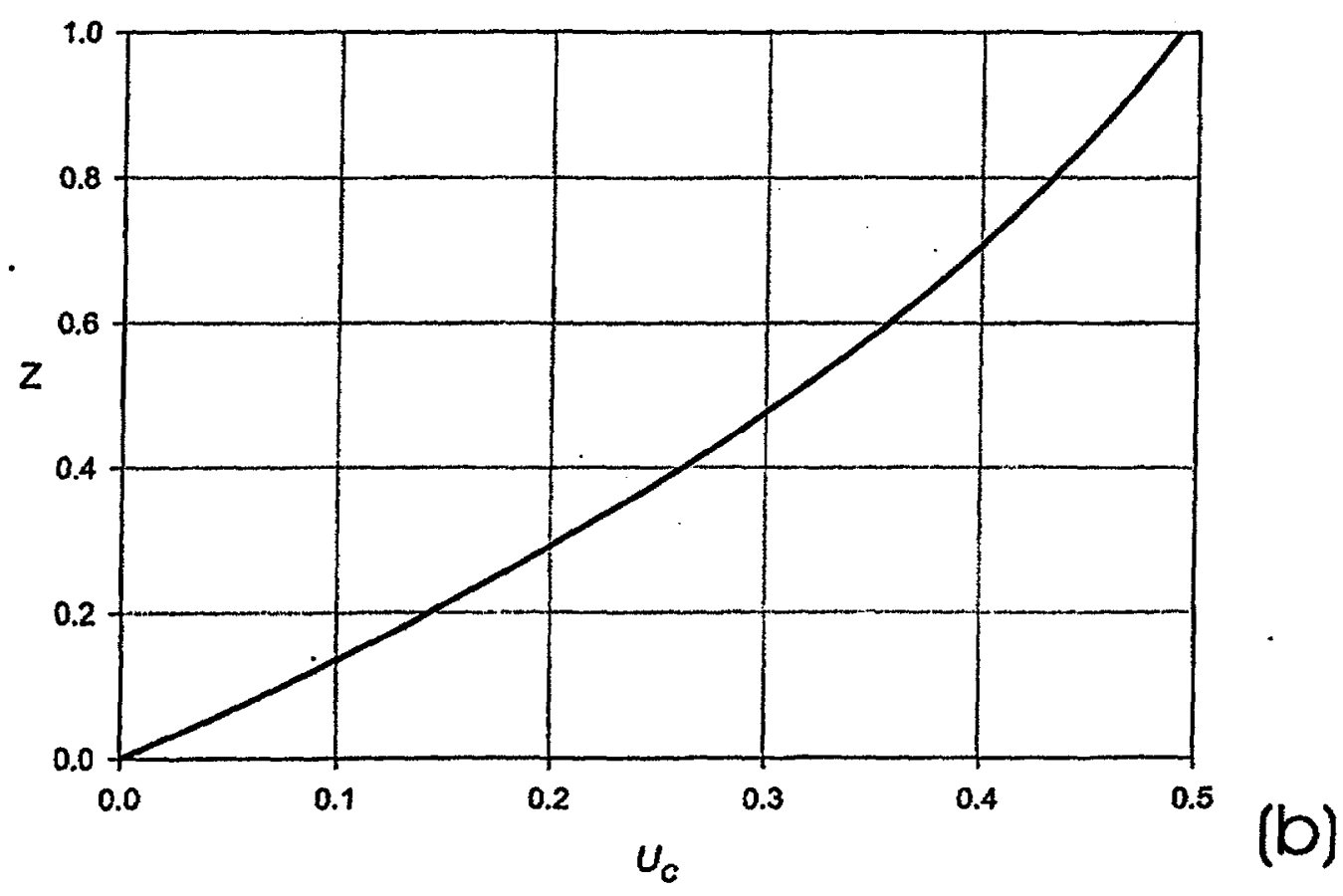

Figure 3.13. Rivulet in a parallel field: electric current lines (a) and velocity profile (b) for $\mathrm{Ha}=100$. 


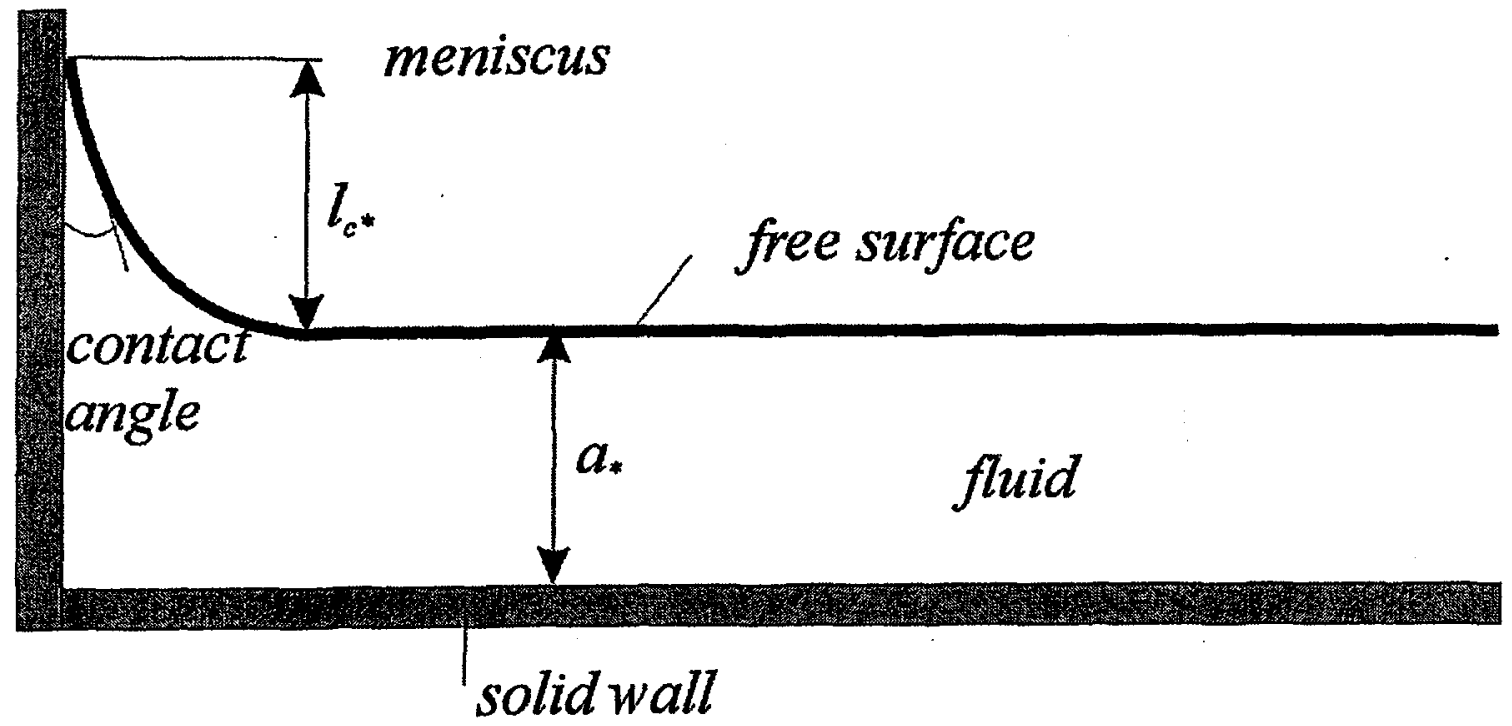

Fig. 3.14 Schematic diagram of the meniscus at the solid sidewall. 